Portland State University

PDXScholar

1979

\title{
Industrial social work : a review of the literature and an evaluation of an employee assistance program
}

Gregory Mark Lee

Portland State University

Follow this and additional works at: https://pdxscholar.library.pdx.edu/open_access_etds

Part of the Mental and Social Health Commons, and the Social Work Commons Let us know how access to this document benefits you.

\section{Recommended Citation}

Lee, Gregory Mark, "Industrial social work : a review of the literature and an evaluation of an employee assistance program" (1979). Dissertations and Theses. Paper 2824.

https://doi.org/10.15760/etd.2818

This Thesis is brought to you for free and open access. It has been accepted for inclusion in Dissertations and Theses by an authorized administrator of PDXScholar. Please contact us if we can make this document more accessible: pdxscholar@pdx.edu. 
INDUSIRTAL SOCIAL WORK: A REVIEW OF THE LITERATURE AND AN EVALUATION

OF AN EN.PLOYEE ASSISTANCE PROTRAN

$$
\text { by }
$$

GREGORY :IARK IEE

A report submitted in partial fulfillment of the requirements for the degree of

MASTER OF

SOCIAL WORK

Portland State University

1979 
TO TIE OFTICE OF GRADUATE STUDIES AND RESEARCH:

The advisor to Gregory Mark Lee approves the research practicum presented June 14, 1979.

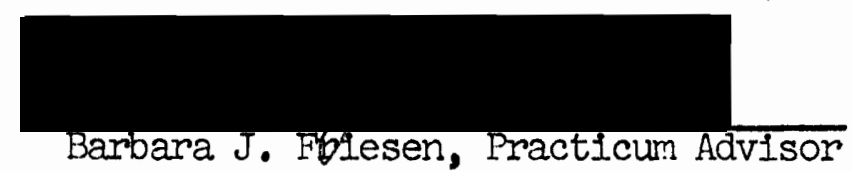


TABLE OF CONTENTS

LIST OF TABLES . . . . . . . . . . . . .

Chapter

I. INTRODUCTION ................. I

II. LITERATURE REVIEW .............. . . . 4

The Meaning of Work ............ . . . 4

Work in Relation to Mental Health and Mental Illness . . . . . . . . . . 7

Community Mental Health and the World of Work . . . . . . . . . . 12

Mental Illness and the Working Population..... 19

A Review of Trends in Mental Health Programing for Worktnp People . . . . . . 26

Description of the Columbia Assistance Program for Employees (CAPE) . . . . . . 32

A Review of Issues Pertinent to the

Evaluation of Employee Assistance Programs . . . . Cost-benefit studies ............. Process versus outcome evaluation . . . . . . Client satisfaction evaluation ........

III. VETHODOLOGY

Determination of Study Desion . . . . . . . . 42

Focus and Objectives of the Study ........ 44

The Data Collection Process .......... 45

IV. DATA ANALYSIS

Characteristics of the Study Population . . . . . 48

Characteristics of the respondents ....... 51

Characteristics of the nonrespondents ..... 54

Discussion of differences between

resnondents and nonrespondents ........

Additional Characteristics of the Respondents . . . 56

Responses to Process-oriented Items . . . . . . . 59

Responses to Outcome-oriented Items........ 61

Responses to Open-ended Items . . . . . . . . 62

Results and Discussion of Cross-tabulations . . . . 65 
Questionna1re Results and Implications .......

Characteristics of the study group and

respondent group . . . . . . . . . . .

Process-oriented 1tem results . . . . . . . .

Outcome-orlented 1tem results . . . . . . . 89

Open-ended 1tem results . . . . . . . . . . 92

Critique of the Nuestionnaire Response Rate . . . . 96

Critique of the Evaluation Process, Study

Group, and Questionnaire .......... . 97

Evaluation Process ............ 97

Study group . . . . . . . . . . . . . 98

Questionnaire .............. . . . . 99

Future Evaluations: Discussion and

Recommendations ........... 101

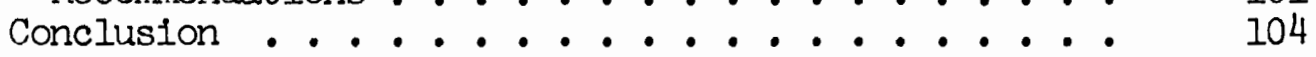

APPENDIX A Copy of Questionnaire and Cover Letter . . ... 106

APPENDIX B Tables of Cormparisons Between Sex and Questionna1re Items .......... 110

APPENDIX C Tables of Comparisons Between Education and Questionnaire Items .......... $\quad 112$

APPENDIX D Tables of Comparisons Between Income and Questionna1re Items .........

APPENDIX E Tables of Comparisons Between Presentinf Problems and Questionnaire Items ......

APPEVDIX F Tables of Comparisons Betiveen Pre-contact Attitude and ouestionnaire Items ......

APPENDIX $\rightarrow$ Tables of Comparisons Between Comfort Seeking

Help and Questionnaire Items .......

LIST OF REEFLRENCES . . . . . . . . . . . . . 


\section{LIST OF TABLES}

TABLE

1. Characteristics of the Study Population . . . . . . .

2. Characteristics of the Respondents

and Nonrespondents . . . . . . . . . . 52

3. Additional Characteristics of the Respondents

4. Clients ${ }^{\prime}$ Information Source Regarding CAP

5. Clients' Report of Vaiting Time

6. Clients' Report of Obstacles for

Fellow Employees ............ 63

7. Clients' Surgestions for Changes

at Work-site ............... 63

8. Clients Sugoestions for Clianges at CAPE . . . . . . 64

9. Clients' Comments or Surpestions . . . . . . . . . . 65

10. Sex by Number of Sessions . . . . . . . . . . . . 66

11. Sex by Satisfaction with Number of Sessions . . . . . . 67

12. Sex by Whether Expectations Were Met . . . . . . . 67

13. Sex by Would Seek Help Elsewhere . . . . . . . . . 68

14. Sex by Overall Satisfaction with CAPE . . . . . . . 69

15. Education by Previous Counseling Experience . . . . . . 69

16. Education by Would Seek Help Elsewhere . . . . . . . 69

17. Income by Comfort Seeking Help . . . . . . . . . . 71

18. Income by Would Seel Help Elsewhere . . . . . . . . . 71

19. Presenting Problem by Would Seek Help Elsewhere . . . . . 72

20. Presenting Problems by Would Seek Help Elsewhere • • . 73

21. Pre-contact Attitude by Comfort Seeking Help . . . . . . 74

22. Pre-contact Attitude by Whether Expectations

Were let ................. 74

23. Pre-contact Attitude by Would Return to CAPE . . . . . 75

24. Previous Counseling by Comfort Seeking Help . . . . . . . 76

25. Previous Counseling by Whether Expectations Were Met . . . . . . . . . . . . 76

26. Previous Counseling by Overall

Satisfaction with Services . . . . . . . 76

27. Work Performance Impaiment by Change

in Work Performance . . . . . . . . . . 78

28. Number of Sessions by Satisfaction with

Number of Sessions . . . . . . . . . . . 78

29. Number of Sessions by Overall Satisfaction

with Services . . . . . . . . . . . 79

30. Client Involvement by Whether Expectations Were Met . . . . . . . . . . . . . . . 
31. Client Involvement by Overall Satisfaction with Services ................... 81

32. Client Involvement by would Returm to CAPE : : 81 


\section{CHAPIEER I}

\section{INTTRODUCTIOST}

One of the more recent trends in mental health programing in general, and soclal work practice in particular, has been the recognition of the world of work as an arena for mental health services. Numerous factors can be identified as contributing to and accompanying this trend in the mental health field. Recent lepislation concerned with the erployment of women, minorities and the disabled has contributed to a changing work force and the emergence of interpersonal concerns among workers (Akabas, Kurzman and Kolben 1979). Business and industry have increasingly found it necessary to acknowledge that workers are human, and that personal problems of vorkers cannot be so easily ignored or dismissed as "private matters," when it becomes apparent that troubled people are troubled workers. Commentators from various ideolocical points of view have addressed the changes in how people view the traditional work ethic. Debate about the meaning of work continues as our society continues its tecinological development in the midst of an inflating economy and rising unemployment.

Concurrently with these forecoing chanpes and avarenesses is the existence of changing perspectlyes for viewing mental 1llness, and the provision of services for those in need. The community mental health movement has brought with it an emphasis on mental health programing; in the commity. The fleld of Industrial social work has sought to 
define the world of work as a conmunity, and as such a target for soclal work practice. Akabas, Kurman and Kolben (1979, p. 5) offer a concise definition of industrial social work, while this description also applies to other professional disciplines involved in the world of work. Industrial social work, therefore, refers to the ut1lization of social work expertise in meeting the needs of workers or union members and the serving of broader organizational goals of the setting. For soclal workers, it offers the opportunity to intervene in a multiple of environmental systems that affect the individual.

The theoretical assumptions and goals of the community mental health movement have brought changes in viewing mental iliness and the delivery of services. However, numerous fallings of this movement have also been apparent. Additionally, mental 1llness and alcohol and drug abuse are recognized by most societal commentators as ever-increasing problems. The emergence of mental health programing in the world of work is conceptualized as responding to the failure of traditional mental health services to adequately serve the needs of the community of work.

In the attempt to explore some of these issues, this report can be considered as having two major goals. The first is to provide a review and discussion of many of the issues that impact on and are part of the industrial social work field. The meaning of work will be discussed, from both an historical and psychological point of view. Aspects of the community mental health ideology will be presented, especially in relation to the world of work. A brief review of various types of mental health programing will be discussed, as well as some of the issues pertinent to evaluation of employee programs.

The second major goal is the presentation of. an evaluation study 
of the Columbia Assistance Program for Employees. The newness of this program, along with the meager existence of evaluation studies of employee programs, resulted in obstacles to evaluation design and data analysis. However, as an exploratory and descriptive study, this report is an effort to assess a program that represents an innovative interface between mental health professionals and working people. 


\section{CHAPTER II}

\section{LTTERATURE REVENW}

\section{The Mearling of Work}

The word for work derives from the Areek work, ponos, meaning solrow. The early freeks regarded work as a curse, the painful price the gods demanded for the goods of life (Tilgher 1962). They felt that work enslaved the worker, was corrupting of the soul, and interfered with the personal independence so highly valued by ancient Greek civilization (Yankelovich 1974). For the Hebrews, the meaning of work was almost as bleak; however, work was painful drudgery, atonement and expiation for the original sin of disobrying the word of God (Yankelovich 1974). Simllarly, the early Christians regarded work as punishment as a result of man's original sin. Work became necessary not only to eam one's living, but also as a means of charity. Work thus began to acquire a certain spiritual dimity.

Historically, changes in the meaning and function of work have been associated with clanres in the economic and social order (Knight 1977). With the development of Christian clvilization arose an accretion of meanings that have evolved into the modern work ethic. The Reformation was the moving force and spiritual revolution which established work as a natural right and duty, as well as the sole legitimate base of society and foundation for property and profit. Whether this new atmosphere, which marked the beginnings of what is known as 
the work ethic, developed out of industrial necessity or religious imperative is still a point of historical controversy. With Luther and the Reformation the nature and meaning of work was significantly altered. "Once, man worked . . to be able to live. Now he worked because somehow it was the right or moral thing to do." (Tilgher 1962, p. II). In contrast to the early freeks, the early Christians saw work as necessary to maintain the health of mind and body. "lartin Luther eliminated the distinction between working; and serving God, and thus work became connected with the moral meanings associated with the moderm American work ethic (Yanikelovich 1974).

The doctrines of Calvinism became part of the foundations of capitalism and moderm business (Knight 1977). To please God it was necessary to work and work hard, and work was to be methodical, disciplined and uniform. In short, work was adjusted to the demands of industrialization and factory settinfs. Predestination had a far reaching and rationalizing implication for the meaning of. work. Wealth and profit were considered signs of hod's favor, so to be poor or dislike work was the greatest disservice to god, as well as a sign of damnation. Remnants of these early Christian beliefs about work remain in the consciousness of moderm Americans, despite the diminishment of such direct connections to religion.

Of particular relevance for this discussion is the idea that one's worthiness is directly linked to one's work activity. Work has acquired far more meaning than mere survival or religious obligation. Work gives people a feeling of being part of a larger society, of having something to do, of having a purpose in lire and is a source of 
status. In essence work continues to be the driving force giving direction and meaning to contemporary living (Nosow and Form 1962). Treud viewed work as man's strongest ties to reality, and implied that if work is the strongest tie to reality, then the absence of work should leave him less solidly in touch with reality (Freud 1961).

Yankelovich (1974), in discussing the results of a study of American values, cited four major themes associated with work:

(1) The "Good provider" theme--the man who provides for his family is the real man, thus there is a link between makine a living and society's definition of masculinity.

(2) The "Independence" theme--to make a Iiving by working is to stand on one's orm two feet and avoid dependence.

(3) The "Self-respect" theme--hard work of any time has dignity whether it be menial or exalted. A man's inherent worth is reflected in the act of working.

(4) The "Success" theme--where hard work leads to success.

Worli is of prime importance in the lives of most Americans, and as Yankelovich suggests in his study, work tends to be invested with vartous dimensions of personal importance and meaning. Whether or not work should have such a prominent place in American society is an engaging question, but not of impcrtance for this discussion.

Work fulfills both explicst functions for people such as survival needs and economic security, as well as less obvious functions. Work contributes to self-esteem and for many people work is a great source of personal satisfaction, an overreaching purpose for existence, an élan vital (O'Toole 1977).

Work is also a princinal source of personal identity, so that who we are is intricately tied to what we do. Vorking also serves to provide order, structure and control in one's daily life, while admittedly 
people have differing needs for such extermal structure. Work is also a source of social contact and ties, so that a work environment also provides a social environment. :lost Americans do work and work does have vital economic, psychological and social functions. Throughout the industrial mental health fleld there is a consensual belief that it is important that people malntain their jobs. This belief stems from the recognition of work as a source of important social and psychological human needs.

Implicit in the foregoing ds.scussion of the numerous functions of work is that work is related to mental health, as well as to mental 1llness. That work is related to mental health is suggested since self-esteem, social ties, ldentity and one's tie to reality are factors affecting mental health in general and intimately tied to one's workIng life. In contrast, if one is without work there is an absence of an important source of self-esteem, social tfes, fdentity and accord with reality.

Work in Relation to Mental Health and Nental Iilness

The previous discussion of the various functions that work serves for people suggests how work is a dominating force in the lives of most people and how it seems to be intrinsically tied to the mental health of peonle. Various researchers have posfted relationships between one's work experlence and Issues of both mental health and mental illness (7oogins 1977; O'Toole 1977; Yankelovich 1974).

One perspective for attempting to understand how work is related to worker mental 1llness is through an analysis of job satisfaction. McLean (1970) surgests that workers' personality disorders, problems 
with alcoholism and drug abuse may stem from job insecurity, unpleasant or hazaridous working conditions. Ginzberch (1967) has pointed out the following sources of worker stress in the work place: isolation, tight supervision, anonymity in rapidly growing organizations, excessive demands on young executives for mobility, technological advances that require employees to be better trained and educated, increased lelsure time for workers who have insufficlent money to pay for recreational activities and preference for hiring the young worker which increases pressure on older workers. Adherence to this perspective for understanding actual or potential mental health problems of. workers results in strategies that revolve around altering the job or work environment.

While studies repeatedly surgest relationships between work and mental iliness, little information is available to clarify the nature of such relationships (O'Toole 1977; Rappaport 1977: Yankelovici 1974). A variety of assumptions are proposed in the literature about the relationshins between work and mental illness. One end of the spectruin emplasizes the oppressiveness of the job itself or the work environment as contributory to worker distress. A logical extension of this assumption leads to strategies to chance the job or work environment, e. E. job enrichment, job sharing, or teamvork on asscmbly lines. At the other extreme is the notion that a worker's personal problems are his own, and that it is his sole responsibility to attend to himself. This attitude implies the belief that the job or work environment has a neutral effect on the mental health or potential mental iliness of a worker. 
Another viewpolnt for understanding the relationships between work and mental illness focuses on the delivery of mental health services to working people. Weiner, Akabas and Sommer (1973) suggest that working people, and particularly blue-collar workers, are an underserved population by traditional mental health agencies. A variety of explanations for why working people are an under-served population have been put forth. Orcanizational obstacles such as inconvenient location of clinics and hours of operation, as well as economic barriers make it more difficult for working people to utilize traditional mental health resources.

Other explanations for why working people are considered an underserved population include the assertion that most mental health agencles are based on middle or upper-class values and norms (Weiner, Akabas and Sommer 1973). Another explanation has to do with attitudes of mental health professionals toward the appropriateness of blue-collar workers for psychologically-orlented treatment. Blue-collar workers are often considered by professionals to be more amenable to medicallyorlented approaches than psychologically-oriented approaches for mental health difficulties (Welner, Akabas and Sommer 1973). Thile this view of blue-collar workers is often voiced as one of the difficulties in providing mental health services to this group, this is not a consistent viewpoint. Gould (1967) surgests that mental health professionals are often simflar in backpround and values to their middle-class clients, and as a result tend to have biased and limited approaches to bluecollar clients.

The reorganization of work at the Volvo factories in Sweden is 
often cited as an examile of how altering the enviroment increases job satisfaction and diminishes problems associated with worker dissatisfaction, alienation and boredorn. An evaluation of the Volvo experiment produced the following results:

(1) Employee tumover was cut by 25 percent.

(2) Absenteeism was reduced by 50 percent.

(3) Recrujtment of new employees became easter.

(4) Quality of the product improved.

(5) Profitablitity was maintained (Gyllenhammer 1973, p. vi..)

It is questionable whether such an approach would be possible, or achieve the same results in an American auto factory, since there are numerous differences between countries. An emphasis on the workplace as the sole cause and solution for mental health problems of workers has inherent limitations. First, restructuring the work environment is a costly, complex, and relatively undeveloped strategy. Furthermore, it is questionable whether it is possible to restructure all workplaces to suft all people. Second, the assumption of a linear relationship between a person's work and mental health or iliness is largely based on 1deological rather than empirical grounds (Weiner, Akabas and Sormer 1973). Third, this perspective tends to have as its primary goals better worker morale, increased productivity and increased nrofits. These are necessary roals for a profit-making; organization, but fail to directly consider as goals the maintenance of worker mental health, or attention to worker problems that may be unrelated to the job or work environment.

Another perspective for understanding and conceptualizing strategies for intervention at the workplace concerns itself with the existing or potential mental health difficulties of workers. Several 
characteristics of this perspective can be distinguished. First, employees and public interest groups are beginning to insist that business and industry have a soclal obligation to recognize and deal with more than productivity, 1.e., to demonstrate concern for the worker as a person, as well as an employee (Googins 1973). Secondly, and perhaps a stronfer incentive for business and industry, is that employees with personal problems contribute to significant economic losses.

In commenting on the involvement of social workers in industrial settings, Austin and Jackson (1977) are critical of the preoccupation with specific client problems and the failure to attend to issues of job satisfaction. Their conclusion is that social workers should structure intervention to reflect both of the aforementioned perspectives:

The involvement of social workers and other members of the human service professions in the delivery of mental health services in industry is a relatively recent development. The provision of such services requires a more comprehensive view of the worker as client, with particular reference to job satisfaction, occupational health, and the mental health services offered by labor unions (Austin and Jackson. 1977, p. 93).

Bearing in mind that the phenomena of work and mental health or illness are extremely complex issues and analyzable from various ideological perspectives, it is not surprising there are diverse strategies for understanding and intervening, in the work environment and with workers. It is also apparent that different professional disciplines have differing, perspectives and areas of expertise for becoming involved with industries and businesses.

Further on in this report various programs for intervening in the world of work will be reviewed, and the ideological underpinnings will 
be discussed. Various programs and professional disciplines have differing conceptualizations for understanding and intervening in the world of work. Such diversity is indicative to both the complexity of the 1ssues of work and 1ts relationship to mental health or mental illness, as well as the tendency of professional disciplines to be selfserving. This report does not attempt to describe or assess the various professional disciplines who are involved in working with business or industry, e.g. how social work differs from psychiatry. This report will, however, be concerned with looking at the various programs and perspectives that reflect the involvement of mental health professionals with working people, businesses, and industries. The interest of the author in mental health and the field of industrial social work has determined the particular focus of this report. Consequently, while it seemed important to briefly review the spectrum of ways for viewing the world of work, primary emphasis here will be on the mental health problems of the working population, and the role of mental health professionals in providing services to this population.

Community Mental Health and the World of Work

This section will discuss the commity mental health movement. Two important reasons can be identified for attention to the community mental health movement. First, the interest in the workplace and workIng people as targets for mental health services can be seen as having its roots in the community mental health movement of the past two decades. Second, many of the objectives characterizing community mental health are consistent with or similar to the objectives of industrial soclal work practice. 
The community mental health movement, begun with the enactment of the Community Mental Health Act in 1963, has resulted in changing ways of thinking about mental illness and of providing mental health services (Bloom 1973). Several key concepts from community mental health are pertinent to a discussion of issues related to the provision of services to working people. No attempt will be made to fully describe the community mental health movement, instead concepts that are directly relevant to industrial mental health services will be revlewed.

One concept in community mental health is emphasis on practice In the community as opposed to practice in institutional settings (Bloom 1973). Related to this is the attempt to identify populations within the community who can be considered at high risk for having or developing, mental health problems. Nkabas and Bellinger (1977) assert that despite this intention of the Community Mental Health Act the functional comminity of work continues to remain outside the mental health delivery system. They conclude that workers are an underserved population as far as mental health care. In a 1975 study in richigan, researchers found that mental health services are underutilized by working people (Helma 1978). Efthim (1976) makes the argument that workers and their families are cut off from the use of mental health services desplte the fact that working people pay for nearly all of the country's human services. Sommer (1969) has described a mental health program with the men's clothing industry in New York City, where the 25,000 workers were viewed as a functional community, and as a target for organizing mental health services. This program seems 
a good example of providing services within the community, as well as identifying a population considered to be at high risk. In this case, it was those workers whose personal problems were interfering with maintaining a job or returning to work.

Another dimension of the community mental health movement has as an objective to insure accessibility and avallability of services. In considering the underutilization of mental health services by working people, various aspects of accessibility and avallablitty have been identified as possible explanations. Helma (1978) offered several explanations for why mental health services are underutilized, even when employee unions cover the costs:

(1) The workers did not know the services were free.

(2) Company physicians, personnel workers, shop foremen, and union stewards were unaccustomed to thinking of working people as candidates for mental health services.

(3) There was an absence of publicity about avallable services and how and when to use them.

Brown (1976) reviewed a study of utilization of mental health services by United Auto workers, and reports that large proportions of the workers and referral agents were unaware of eligibility for services, and possessed Ifttle information about the nature of services or how to use them.

Levenson (1970) suggests that community mental health programs could become a more important resource for the worker and his family. For example, by being geographically accessible, economically affordable, and avallable on wéekends and evenings, programs could better provide services for working people.

Akabas and Bellinger (1977) explain the underutilization of 
mental health services by working people as partially due to mental health professionals and program policies, e.g. by fees that create economic barriers, waiting lists, inconvenient hours, and by defining workers as unpromising candidates for treatment. In discussing accessibility to community mental health programs, Levenson (1970) asserts that programs must be psychologically accessible as well as geographically accessible. He suggests that clients need to feel comfortable seektng help, and Importantly, that help-seeking behavior needs to be approved of and endorsed by one's immediate community. This dimension of accessibility is particularly important for understanding and remedying the underutilization of mental health services by working people. Akabas and Bellinger (1977) suggest that workers tend to not define their distress in psychological terms, distrust the mental health care system, and fear calling on outsiders for help with personal problems. In discussing obstacles to treatment for blue-collar workers, Brown (1976) states that the continued stigma of mental iliness keeps people away, from treatment. Benedict (1973), in describing his experience providing mental health services to employees of a trucking company, suggests that blue-collar workers resist depending on a counselor for assistance "because they have always made it on their own."

Stone and Crowthers (1972), in assessing the implementation of a mental health program for auto workers concluded that gaining acceptance of their program by blue-collar families was the greatest problem. They reported that apathy, fear, suspicion and misinformation on the part of blue-collar workers contributed to reluctance to 
utilize avallable services (Stone and Crowthers 1972). Another explanation for the reluctance of blue-collar workers to use available services had to do with their concern with confidentiality, being concermed that employers would be informed of their having mental health problems (Stone and Judson 1972). Riesman and Scribner (1965) suggest that the reluctance of blue-collar workers to utilize mental health services may be exacerbated by the fact that when blue-collar or low-income people do have contact with mental health services, they are more likely to be institutionallzed or relegated to only medical treatment, more of.ten than middle or upper-class clients. Instead of re-educating blue-collar workers about mental illness and available services, the mental health profession and service institutions have contributed to the blue-collar worker's nergative attitudes about mental health problems in general (Miesman and Scribner 1965).

Benedict's (1973) stratery for overcoming the resistance of bluecollar workers to using mental health services was to enter the workplace, maintaining, a hiph depree of visibility, and seeing clients outside the traditional office setting. Alrabas and Bellinger (1977) describe a training program for union representatives, shop stewards, business agents and union counselors where the intent was to equip these indigenous helpers to identify employees in trouble, refer such workers for appropriate care and help protect their jobs. This training program was considered a direct method for breaking the barmiers to working people receiving needed mental health care.

A complete analysis of the bamplers to accessbility and availabjlity is not possible here, yet it is apparent that such barriers 
exist, and particularly for the working population. The characteristics of traditional mental health services, the attitudes and approaches of mental health professionals, and personal and cultural values of worling people have all contributed to the tendency of working people to be an underserved population by traditional mental health services.

Another dimension of the community mental health movement is emphasis on preventive services. Various types of prevention are distingulshed, while all are concemed with the prevention of mental illness (Bloom 1973). Primary prevention efforts are designed to prevent the 1liness from ever occurring. Efforts at secondary prevention are designed to develop techniques for early identification and early intervention. Tertiary prevention strategies are concemed with limiting the disability assoctated with a particular illness or problem. : Consequently, primary prevention programs seek to reduce prevalence by reducing incidence, while secondary and tertiary prevention programs seek to reduce prevalence by reducing the duration of mental iliness (Bloom 1973).

Several aspects of the organization of mental health services for working people can be ldentified as functioning on a preventive level. By training; shop stewards, union representatives and others In the workplace who have daily contact with employees, early identification and intervention are more likely. As earlier discussed, work is intricately linked to varlous aspects of mental health and mental 11lness. Based on this vfewpoint, Alrabas and Akabas (1978) advocate services for workers who are in danfer of slipping out of the labor 
force due to emotional problems. In supporting work settings which sponsor programs for the maintenance of emotionally troubled workers, Akabas and Akabas (1978) suggest that such a program demonstrates the value that it is acceptable to have and recelve assistance for mental health problems. By making services avallable in the workplace and combating the stigma of mental illness or the stigma of obtaining help, such programs can be considered to function on both secondary and tertiary levels of prevention.

Preventive mental health is not explicitly conceptualized as a program goal by all of the professionals working with businesses and industries. However, if the provision of mental health services to employees serves to improve or maintain mental health, as well as to intermupt job performance deterioration, then prevention can be considered an outcome.

Other dimensions of community mental health that are related to prevention include an emphasis on consultation and education. Bloom (1973) defines consultation as when a mental health professional works with a primary caretaking system rather than directly with the system's clientele, in an effort to make a meaningful intervention in the lives of a defined population. An apt example is provided by Akabas and Bellinger (1977) in their description of a training program and consultation service for shop stewards, foremen, and other key helpers In the workplace. Through training, consultation, and education these Indigenous helpers obtained the skills, knowledge, and support to identify peers in trouble, refer troubled employees to appropriate services, and assist troubled workers in maintaining their jobs (Akabas 
and Bellinger 1977). Helma (1973) reported that the absence of systemat1c methods for disseminating information about avaliable mental health services was a major cause of underutilization of avallable services by working people. Stone and Crowthers (1972) maintain that education can be important for several reasons. Education can provide Information about available services and can be used to break down barriers to the acceptance of mental health intervention. Furthermore, education can be useful in the aim to promote early identification of the emotional problems experfenced by working people.

This section discussed some of the concepts that are features of the cormunity mental health movernent and consistent with characteristics of mental health programing in the world of work. Of particular relevance for this report on mental health services for working people are the concepts of accessibillty and avaliability of services. The next section will discuss the prevalence of mental illness, with particular emphasis on the working population.

\section{Mental Illness and the Worling Population}

In reviewing methods for assessing the prevalence of mental health problems among American workers, two major emphases can be identified. Tirst, investigations can focus directly on assessing the incidence of mental health problems in the worker population. A second, and indirect method, is to focus on the worli-performance problems that can be inferred to be caused or reflective of the personal problems of worling people. In this section each of these emphases will be considered.

Dahl et al. (1978) cite a recent study by the National Institute 
on Alcohol Abuse and Alcoholism where ten percent of any labor force were identifled as troubled workers. Half of these are in the early stages of alcoholism or are overtly addicted to alcohol, while the other half experience a varlety of mental or medical problems (Dahl et al. 1978). Helma (1978) cites a study by the Michigan Department of Mental Health and Michigan State University where thirty-nine percent of employers surveyed reported awareness of employees with mental health problems.

In a recent report published by the Bureau of National Affairs, a personal crisis situation was found to be the most prevalent problem among all employer groups (Bureau of National Affairs 1978). In this survey of 65 employers from both small and large companies, eleven percent of production workers, seven percent of clerical workers, six percent of technical or professional staff, and six percent of managerial personnel were considered to be experiencing a personal crisis situation involving marital or family troubles. In this same survey alcoholism was ranked as the next most prevalent problem, affecting five percent of both professional and managerial staff, four percent of clerical employees and eight percent of the production or service group. These studies of employer perceptions of prevalence of problems among employees can only be considered as suggestive information, as the data is based on oplnions as opposed to a systematic diagnostic process. Rappaport, Dolan and Clement1 (1977) cited research indicating twenty-flve percent of the industrlal employee population have signifcant emotional problems and ten percent have serious psychiatric impairment requiring an excessive amount of time and energy from super- 
visors. Rappaport, Dolan and Clementi (1977) also cited a study of four thousand workers discharged from their jobs, where sixty-two percent were fired for reasons of personality maladjustment rather than job performance problems.

Information about prevalence of mental health problems in the employed population can be hypothesized by considering surveys of the American population as a whole. Joerger (1978) cites the study of the population of. "iidtown Manhattan where twenty-five percent of individuals surveyed were in need of some type of mental health care. A more recent report by the President's Commission on Mental Health estimated that between fifteen and tiventy percent of the population had diagnosable mental health problems and were in need of treatment (Joerger 1978). Such global surveys of the prevalence of mental illness can only be viewed as rough estimates of prevalence in particular employee populations.

One of the conclusions made in the community mental health literature and in industrial social work articles is that working people are an underserved population by traditional mental health services (Akabas and Bellinger 1977). This commentary on the mental health delivery system suggests that a portion of the employee population have mental health problems and are not receiving needed care. Efthilm (1976, p. 31) provides substantiating evidence provided by research results from insurance company studies of utilization:

It is estimated that 15 million persons are now covered for outpatient mental health care by labor-management contracts with Blue-Cross-Blue Shield and other insurance carriers. Less than 2 percent of those eligible actually use these benefits, although actuarial specialists indicate that at least 10 percent of any potentially insured popu- 
lation really needs mental health services.

Numerous obstacles are identifiable in the attempts to estinate the prevalence and incidence of mental health problems in the working population. One apparent difficulty is expecting employers, who are not trained and educated mental health diagnosticians, to provide such Information. Most likely a particular employer would only have his personal experience and attitudes regarding mental illness to draw upon, so results would be highly personalized and of questionable reliability and validity. Another difficulty has to do with the comlexity of determining what constitutes mental health problems, particularly prior to an individual's acknowledgement of personal mental health difficulties. This reflects the difficulty of establishing and implementing preventive mental health programs in general. Furthermore, issues surrounding the stigma of having mental health problems and seeking help probably contribute to the difficulty in gathering such information about a specific population.

Another strategy for assessing the incidence and prevalence of mental 1llness in working populations has been to look at job performance problems. Divergences in ideological perspective often occur here, as one can look at the work environment as causing the job performance problems, or one can look at the individual worker as the object of diagnosis and intervention. In choosing to look at the mental health problems of workers in relation to job performance problems, several value judgements and assumptions are impliclt. First, that work is important for people and their mental health and that the two are related. Second, that an appropriate goal for mental health pro- 
fessionals involved with business and industry is to assist employees in maintaining both their jobs and their mental health. Third, that mental health problerns of working people are likely to be manifested at times in the workplace. Fourth, that attributing worker mental health problems solely to the fob or work environment is too simplistic and, in fact, not an accurate explanation. As will be discussed later in this report, many programs aimed at providing mental health services to workers utilize the emphasis on job performance for Identifying workers with mental health problems and for measuring the effectiveness of. mental health services.

Joerger (1978) reviews several studies that suggest a relationship between the rate of absenteelsm experlenced by an organization and the inctdence and prevalence of employee personal problems that affect job performance. For example, it was found that employees having alcohol problems were absent four times more frequently than. the average worker, while those having drug, mental health, or family problems were absent five times more frequently than the average hourly worker in the same organization (Joerger 1978). According to recent studies by the National Institute on Alcohol Abuse and Alcoholism, about ten percent of any labor force are troubled workers whose job performance has deterforated (Florida Department of Health and Rehabilitative Services 1978). Half of this group were found to be having serious alcohol problems, while the other half were experiencing mental health or medical problems (Dahl et al. 1978). A recent Psychology. Today article reports that General flotors has major problems with employee absenteelsm, alcoholism, careless workmanship, and other prob- 
lens assumed to be related to mental health or mental illness (Collier. 1973). While such results suggest relationships between job performance problems perceived by management and the mental health problems of employees, it is questionable whether the findings at General Motors can be generalized to other companies or industries.

When job performance is used as a method for identifying potential or existing mental health problems of employees, attempts have also been made to translate incldence and prevalence of problems into economic losses for the company. Translating the data regarding employee mental health problems into economic losses for an organization is often a strategy for convincing management to fund mental health propraming for employees. In a survey that looked at the $2,695,079$ civilian employees in Florida, it was estimated that ten percent of this total group had mental health or medical problens (Dahl et al. 1978). Based on this estimate of prevalence, it was further estimated that this group of employees with problems cost their employers $\$ 522,860,716$ in wasted payroll dollars (Dahl et al. 1978).

Employee problems have been hypothesized to affect job performance in a number of ways. Some manifestations of personal problems in the workplace include: late arrivals and early departures, absenteeism, poor judgement, erratic and decreased productivity, failure to meet schedules, lowered morale, resentment among other erployees, waste of supervisory time, and damaged customer and public relations. Direct economic losses are manifested in various ways as well: excessive use of sick leave, increased workmen compensation costs, increased group medical insurance rates, and adverse effects on profit-sharing programs. 
In general emphasis on job performance has been used as both a strategy for identifying potential or existing employee mental health problems, as well as for marketing the concept of mental health programming to management.

Strategies that attempt to identify and understand relationships between mental health problems and job performance have both positive attributes and limitations or drawbacks. One potential problem would be the mistaking of any job performance problem as a symptom of mental 1liness. In some cases the personal problems of an employee may be the primary cause of job performance impairment. It is also possible that job performance impairment could have other primary causes, e.g. management problems, troubled employee-employer relationships, or work environment problems. Consequently, an emphasis on mental health problems as related to job performance would need to also allow for other possible explanations of job performance difficulties.

The emphasis on the links between mental health problems and job performance does seem a promising strategy for approaching and intervening in the workplace for several reasons. First, mental health problems of employees will, at times, become manifested in job performance problems. Second, the process of focusing on both personal problems and job performance can imply or demonstrate an acknowledgement of the importance of maintaining both mental health and good work performance. Third, through focusing on job performance as a strategy for assisting troubled workers, the likelihood of preventing job loss due to personal problems could be enhanced. And fourth, if it is assumed that mental health problems interfere with successful job per- 
formance, effective intervention can be both beneficial to the employee as well as to the organization.

\section{A Review of Irends in Mental Health Programing for Worktng People}

An in-depth historical review of attempts to provide mental health services to worktng people has been provided by "IcLean (1966). The past decade is of most relevance for this renort, as recently there has been a resurgence of interest by soclal workers in the world of work (Austin and Jackson.1977). Thurthermore, in recent years as social workers and other mental health professionals have become involved with the world of work, a variety of program philosophies and strategies have emanated. As a fairly new field of intervention for mental health professionals, there exists a great amount of experimentation in program design, delivery, and financing. This section will review some of the programmatic trends in the involvement of mental health professionals with the working world.

While there exists a resurgence of interest in mental health issues and the working population, alcohol programs for employees have existed for many years. Alcohol-focused prograns in the workplace are of consequence for this review, as alcohol programs were the foremunners of contemorary programs that deal with a range of employee personal problems. Initial alcohol programs were intended for employees identifled as alcoholics and typically used the threat of job loss as a coercive element (Akabas 1977). Several major concerms of mental health professionals regarding the circumscribed purpose and methods of these programs can be identified. 
These early alcohol programs tended to focus on only latterstage alcoholics and in the process of attempting to identify alcoholics two major negative consequences became apparent. First, entployees were inadvertently discouraged from voluntarily admitting problems with alcohol. Second, in the pursuit to label alcoholics among the employee population these programs functioned to stimatize identifled employees. Another objection to these programs was the failure to provide services for employees having other mental health problems, or not recognizing that some employees may have developing alcohol problems, yet not be latter-stage alcoholics. A further objection to the emphasis of such alcohol programs was the exclusive focus on rehabllitation of chronlc alcoholics and the lack of a preventative mental health emphasis. Despite such criticisms it seems Important to acknowledge this segment of the trend in mental health programing with working people. In many ways these programs are the foundation for later, more comprehensive mental health programs in business and industry. Roman (1975), Thice (1970), Tapscott (1978) and Smart (1974) have all discussed various forms of alcohol programs in the working world and examine the effectiveness of such program efforts. Another type of program, often referred to as in-house counseling, is located at the worksite and provides services to employees with a range of problems. These programs are sponsored by management, the unions, or both, and tend to exist in large businesses or industries. Most often these programs are part of the company personnel or medical department. Counseling can be provided by the in-house staff or through referrals to commity agencles. Each company's program will 
differ depending on the orientation of staff. and management. While some programs will emphasize referrals from supervisors, others will emphasize comprehensive services for voluntary employees. Akabas and Bellinger (1977) have addressed some of the advantages and disadvantages of such "in-house" programs. One advantage is that such programs may have greater sanction to intervene within the organization, since they are a part of the organization. Another suggested advantage of such programs is that they may have a better chance of being incorporated into the structure of the organization, and consequently be less likely to be cut from the budget. A critical issue for this type of program, especially when hired by management, concerns for whom the counselor is working (Akabas and Bellinger 1977). This is a potentially confusing dilemma, both in the minds of employees and counselors, and requires explicit clarification of roles and responsibilities by the counseline staff. Confusion as to the proper role of the mental health professional could be a potential difficulty in such programs, where the mental health profession is simultaneously an employee of the organization and an advocate or confidential helpel for other employees. Another segment of the recent trend in mental health programming for working people is where unions or management contract with extermal mental health agencies to provide services to employees. Family service agencies, communtty mental health programs, and private practitioners have been responsible for most of these kinds of contractual services to workers. Again there is a wide variety in the types of services that are made available to workers. There is also a range of emphases, as some contractual arrangements might emphasize treatment of 
employees with alcohol or drug problems, while others might emphasize assistance for personal or family crises. A particularly impressive example of this type of programing is described by Welssman (1976), where a large steel company contracted with a private social work consulting firm. Brooks (1975) provides an interesting account of the implementation of a service contract between a family counseling agency, and a conglomerate whose subsidiaries included various manufacturing companies.

The resurgence of Interest in mental health programing with business and Industry has brought with it changes in the language. In recent years the term employee assistance program (EAP) has become an encompassing neologism to refer to the attempts of mental health professionals to provide mental health services to workers. Difficulties with and objections to the circumscribed structure of alcohol programs led to attempts to amplify the goals and objectives of programing in the workplace. Consequently, the term EAP has come to reflect this expansion of programmatic interest. In reviewing the literature it is apparent that the term EAP is used in many ways, so that some traditional alcohol programs call themselves EAPs while for other writers an EAP is a comprehensive system of service provision for an organization. This latter meaning of EAP is used most frequently in the literature. For purposes here EAP wIll refer to those programs which provide comprehensive services in the world of work. The term "broadbrush" employee assistance program is the most recent term for distinguishing EAPs which provide a range of services as contrasted with the earlier alcohol programs. The remainder of this section will de- 
scrtbe the most common components of comprehensive or "broad-brush" employee assistance programs.

Most employee assistance programs include the establishment of policies and procedures pertaining to: employees with work-inindering problems, the acknowledgement that employees have personal problems, the insurance of confidentiality, the insurance of service avaliability and accessibility, and the proper roles of management, supervisors, employees and counseling staff. Such policies and procedures can be established in varlous ways, most often normal organizational channels. such as memos or newsletters are utilized to disseminate this information. Policies and procedures will vary according to organizations and interests of mental health professionals, but in general EAPs have explic1t guldelines regarding most of the above issues.

Another element to EAPs is the focus on training of supervisors in an organization (Googins 1975; Hellan and Tisone n.d.). It is considered essential to the utilization and effectiveness of an EAP that supervisors fully understand the philosophy and functions of the program (Googins .1975). Training is provided to supervisors on policies, procedures, role expectations, and particularly how to intervene with an employee who is demonstrating deteriorating work performance. EAPs typically work with a company to establish a system for training supervisors to use standards of job performance as an opportunity for early 1dentiflcation of troubled employees (Hellan and Misone n.d.). The EAP staff will also provide consultation to supervisors around issues of documenting, identifying, and confronting job performance difficulties. 
performance difficulties.

Several assumptions typically characterizing EAPs are underpinnings for the emphasis on the training and education for supervisors. First, the personal problems of employees are often manifested in the work-place as deteriorating or poor job performance. Second, the proper role of supervisors is to measure and evaluate job performance, not to diagnose and treat the personal problems of emoloyees. Training is thus Intended to have supervisors attend to poor job performance, viewing that as a clue the employee is possibly experiencing some kind of personal difficulty. Functloning in this way, this element of an EAP provides a preventive intervention since an employee can get assistance before personal problems persist, or before job performance deterioration endangers the employee's job security. A further benefit of trainIng supervisors to attend to job performance standards is that; 1deally, employees are motivated to obtain personal assistance to retain their jobs.

The actual services offered by EAPs vary from program to program, both in emphasis and comprehensiveness. The previously mentioned emphasis on job performance, as well as the provision of a range of services, are the main features of EAPs. This distinguishes them from alcohol programs, in-house counseling programs, or contractual arrangements with community agencles. Services can be provided for such problems as emotional difficulties, marital and family conflicts, complex legal or financtal problems, drug and alcohol problems, and job performance difficulties. An EAP may provide assistance to employees having some of these problems and provide a refermal service for other 
Identified problems. If employees are referred to outside resources, the EAP staff typically provicle thorough follow-up contact. This is done to assure that the employee is using the service and to evaluate the sultability of the service for that employee.

Employee assistance programs represent a stage in the gradually evolving field designed to meet the needs of employees with problems (Googins 1975). The variety of program designs that have developed In recent years reflects the experimentation of mental health prom fessionals in their involvement with the world of work. Emoloyee assistance programs tend to be grounded on several pinllosopinical and pragmatic notions. First, that work is important to people and that most people want to work. Second, that assistance to employees should be geared toward the maintenance of an emplovee's job and the resolution of his persional problems. Third, that EAPs can simultaneously serve the needs of employees and manafement. This simultaneity occurs when employees recelve assistance for their personal problems, and management benefits economically when the job performance manifestations of employee problems are reduced or eliminated.

In the next section a description of the Columbia Assistance Program for Employees will be provided. This propram is an example of a broad-brush emplovee assistance program and is characterized by many of the elements of EAPs in general, and, as described in this section.

\section{Description of the Columbia Assistance} Program for tholoyees (CAPE)

This section is intended to provide an overview of the employee 
assistance program that is the target of this evaluation effort. The inception of what is now the Columbla Assistance Program for Employees can be traced back to the summer of 1976. At that time several staff members from the Clackamas County Mental Health Clinic were considering strategies for expanding services into the community. The population of employees in area businesses and industries was considered a viable target for out-reach efforts. Initially the idea was to form an industrial branch to the county mental health clinic; however, this idea was discarded for various reasons and what eventually emerged was a private, corporate model. An instrumental factor in the development of what is now CAPE was the engagement in a consulting relationship with the Columbia University Industrial Social Welfare Center. Without detaling all of the phases in the development of funding sources, administrative structure and program philosophy, CAPE is presently a private, non-profit employee assistance program. Funding is partially provided by the Clackamas County Mental Health Clinic and the Oregon Mental Health Division, through contracts for services with businesses and industries, and continues in the federally-funded consulting relationship with Columbia University.

CAPE is characterized by most of the elements previously mentioned in the description of broad-brush employee assistance programs. CAPE is conceptualized as serving two broad goals. The first is to work with Portland-area business and industry to reduce their economic costs steming from employee mental health and social welfare problems. The second broad goal is to deliver and advocate services directly to and for the working population. Three areas of objectives can be 
Identified as the attempts to accomplish these dual goals:

(1) Train, educate and consult with supervisors and managers in dealing with employee problems.

(2) Provide a range of direct services to employees and immediate family members for alcohol, drug, marital, family, financial, legal, and individual psychological problems. Act as referral agents when necessary, then provide follow-up at CAPE offices or at the work-site.

(3) Advocate cormunity services for employed people, including treatment resources covered by company insurance plans, community clinics, and in-patient facilities (Talkington 1978)..

Upon contracting with a company, CAPE works with that organization to develop a system for providing services to the employees. Typically a key individual, such as an occupational nurse or personnel director, is closely worked with to tailor the services to that particular company. A variety of companies share the services, staff, and knowledge of the CAPE program, thus enabling small companies to afford the benefits of an employee assistance program. The cost to a company is directly based on the number of employees. While the system that is developed for each company to provide services to their employees varies somewhat among companies, a typical system will include the following dimensions:

(1) Detailed planning of program elements prior to implementation to assure early utilization and acceptance.

(2) Consultation on developing program policies and procedures that are compatible with current personnel practices.

(3) Program promotion materials to assure visibility and to encourage employee assistance.

(4) Assistance in developing program manuals for supervisors, containing program policies, procedures; and guldelines for the supervisors' role.

(5) Supervisor education and training sessions to assure an effective program for employees and for the organization. 
(6) Professional, confidential, and convenient assessment and counseling services for employees and/or Immediate family members.

(7) Two types of periodic program feedback:

a) monthly reports on usage of CAPE services by company employees (statistics and demographics, not identification of individuals).

b) Research assistance on cost-effectiveness studies (Talkington 1978).

At the present time CAPE staff is composed of a director (psychologist), a training coordinator (psychologist), an M.S.W. social worker, one clerical staff, and two graduate social work students. At the time of the survey, CAPE was in contract with five Portland-area companies. Included were two industrial manufacturing companies (with 130 and 200 employees), a veterinary clinic (with 5 employees), a medical hospital (with 300 employees) and a school district (with 1,200 employees). The present study was directed at the clients who came from these five employee groups. In recent months CAPE has contracted with several other firms, including an industrial corporation (with 1,100 employees) and a legal firm (with 100 employees). Just recently CAPE contracted with the City of Portland (with 4,000 employees) to provide an alcohol assessment and referral service for c1ty employees referred by supervisors. This latter deviates from the broad-brush employee assistance program model, but was considered a step in the direction of establishment of a contract for fill employee services.

\section{A Revilew of Issues Pertinent to the Evaluation of Employee Assistance Programs}

While demand has been growing in the past, several years for evaluation of mental health programs in general, programs for employees 
have also been targeted for evaluation efrorts. This section will address several issues pertinent to the evaluation of employee assistance programs. First, cost-benefit analysis as a strategy for evaluating emplovee programs will be presented. Second, the issue of process versus outcome evaluation studies will be discussed. Third, the use of client satisfaction measures for evaluation of mental health programs will be revieved.

A review of the literature on evaluation of employee programs reveals that outcome evaluations of job-based alcohol programs are most frequently reported (Trice, Beyer and Hunt 1978). Outcome measures have been defined in terms of reduced costs to employees, e.g. reduced absenteeism, reduced medical utilization and sicl leave, decreased accidents, reduced employee turmover and increased productivity. Although little information exists in the literature on attempts to evaluate broad-brush employee assistance programs, descriptions of most employee assistance programs assert that their prosrams are, or can be, economically beneficial to business and industry.

\section{Cost-benefit studies}

A recent article in The New York Times reported on a study of an employee counseling program where 150 employees were measured a year before entering the program and a year after leaving. Results indicated a fifty-two percent decrease in absenteeism, a seventy-five percent decrease in weekly beneflts for absent workers, and a fifty-five percent decrease in hospital, medical and surgical costs (New York Times 1 April 1979). Other evaluation studies of emoloyee programs attempt to translate prongram effectiveness into monetary terms. Wiegard 
(1972) reported on a company alcohol propran that resulted in an annual savings in sick time alone of over $\$ 2$ million. Otto Jones, head of a private social work agency that provides services to companies on a contract basis, says that his procrems realize a $\$ 3.10$ return on each dollar invested hy the contracting company (New York Times I April 1979).

In general cost-benefft studles attempt to demonstrate that an employee assistance program saves money for a business or industry. These evaluation studies make tivo fundamental assurmtions. First, that employee personal problems are being manifested in company costs such as medical utilization, absenteeism, accidents, and decreased productivity. Second, that changes in rates of absenteelsm, medical utilization, etc., demonstrate program effectiveness and successful resolution of employee problems.

The almost exclusive emphasis on cost-benefit as a measure of program effectiveness has both positive and negative aspects. Emphasis on cost-benefit addresses management's interest in maintaining a product1ve work-force. This emphasis also provides numerical data that may be useful in the marketing of employee assistance programs. Several Iimitations to an exclusive attention to cost-benefit can also be identified. While cost-benefit studies address the coimon EAP goal of reducing company costs, they do not directly consider the changes in personal functioning of employees, which is another fundamental goal of employee programs. While cost-benefit is considered an outcome measure, this emphasis falls to address the question of which variables are responsible for changes in job performance. Also, as an outcome measure, cost-benefit is appropriate for use only after a program has 
been established. This emphasis thus falls to consider the process of implementing a program.

Process versus outcome evaluation

An alternative strategy of mental health program evaluation looks at program process rather than outcome (Chommie and Hudson 1974). Attending to program process can lead to the discovery of information that explains outcomes, makes goals specific, and improves the delivery of services (Chommie and Hudson 1974). While funding sources may require or be more attuned to outcome evaluation, e.g., cost-benefit analyses, research on the processes of propram implementation can provide information useful to program administrator, staff, or clients.

Trice, Beyer and Hunt (1978) reported on a study which assessed the implementation of a job-based alcoholism program and policy for employees of the U.S. Civil Service Commission. Two reasons were put forth for an assessment of the implementation process rather than outcome. First, that process evaluation is necessary because the original goals of a program are frequently unstable, and the assessment of program implementation can reveal changes in program goals. Second, when a program policy is new, the evaluation of outcome is premature and does not provide information to managers for helping them make decisions that will keep their programs on course (Trice, Beyer and Hunt 1978).

In reviewing problems inherent in the utilization of an experimental design for the appraisal of the effects of a "broad-aim, largely unstandardized, and Inadequately replicated program," Weiss and Rein (1970) justify and advocate evaluation strategles that are more qualitative and process-orlented. They suggest such an emphasis would be 
concermed with the way in which a program makes a place for itself, the way the system accomodates itself to the program, and the reactions of individuals and institutions to program implementation (We1ss and Rein 1970). Brooks (1971) asserts that several questions need to be addressed in process-oriented approaches to evaluation. One is, what people become involved and with what effects? Another is, why does the program reach some people and not others?

The justifications for the utilization of process-oriented evaluation strategies are relevant to evaluations of employee assistance programs on several levels. First, many employee assistance programs have only recently evolved, so implementation of services is an Important issue. Second, a fundamental assumption of most employee programs is that working people have been an underserved population by traditional mental health agencies. Consequently, the issues of accessibility and availability of services seem important. Processorlented evaluation studies would be more apt to gauge these program objectives.

Client satisfaction evaluation

Process-orlented evaluation seeks different information than outcome-oriented evaluation and requires the use of alternative measures. The assessment of client satisfaction can be used to measure various aspects of program services. Attkisson, Hargreaves, Horowitz and Sorensen (1978) supgrest that client satisfaction ratings are most suitable for monitoring program quality. The basic purpose of program monitoring is to detect problems or conditions that require closer examination. O'Neal (1971), in reporting on a client satisfaction study 
of a mental health clinic, advocates this strategy for gaining a better perspective about the services provided, and for increasing the effectiveness in the delivery of services. McPhee, Zussman and Joss (1975) comment on the potential usefulness of client satisfaction measures, but consider the concept too simplistic when assessments merely consist of questions regarding the satisfaction with services. They conclude that a multi-dimensional concept of satisfaction is ncessary, including such factors as satisfaction with accessibility, apparent professional skillfulness, and physical surroundings (.IcPhee, Zussman and Joss 1975).

The most frequently discussed limitation or difficulty with client satisfaction studies has to do with the interpretation of results. Attkisson, Hargreaves, Horowitz and Sorensen (1978) comment that without comparisons to other similar programs or within the same program over time, it is difficult to determine how much the results are influenced by blases to include only satisfled clients, or response biases to report what seems to be expected. Client satisfaction studies that emphasize outcome are particularly subject to biases and difficulties in the interpretation of results. MicPhee, Zussman and Joss (1975), in surveying the use of client satisfaction measures by community mental health programs, report that emphasis on outcome is the least valid use of client satisfaction strategies. They suggest that outcome is the area in which clients are least able to judge, and cite findings where clients were satisfied with services even though client outcome was poor (McPhee, Zussman and Joss 1975). Implicit to this argument is the Iimitation of client satisfaction measures, where 
client satisfaction cannot necessarily be equated with favorable outcome. Client satisfaction measures can also emphasize program process, when such aspects as satisfaction with waiting time and number of appointments are addressed. Used in this way client satisfaction measures can be a monitoring device to provide information to program staff and administrators. While client satisfaction measures can address both process and outcome dimensions of a program, the literature suggests client satisfaction has the most potential for addressing process 1ssues.

This section contains an overview of several issues pertinent to the evaluation of employee assistance programs. Cost-benefit analysis was brlefly discussed since it tends to be the most common strategy in evaluating employee assistance programs. Some of the 1ssues surroundIng the cholce of outcome or process-orlented evaluation were reviewed. Finally client satisfaction was discussed, in terms of looking at both process and outcome dimensions of a program. This section is a preIiminary to the next chapter, which is a description of the methodology. 
CHAPTE? III

IETIODOLOGY

This chapter discusses evaluation planning and data collection for the evaluation of the Columbia Assistance Program for Employees. The first section discusses the determination of study design. The second section presents the focus and objectives of the study. The third section addresses the data collecting process.

\section{Determination of Study Design}

A variety of factors influenced both the decision to conduct an evaluation study of the CAPE program and the stratery for doing so. The author's interest in the field of industrial soclal work was the impetus for proposing a research project at CAPE. Several characteristics of the CAPE program limited the number or feasible evaluation strategies. First, as a fairly new program the total number of clients who had been served was limited. This was a contraindication for attempting an assessment of client outcome. Because of the snall nurber of. clients who had been seen and terminated, a cost-benefit analysis would have been premature as an evaluation strategy. Second, gaining access to personnel records for data on absenteelsm, medical utilization and accidents was considered an obstacle. rifird, the record keeping system was in a developing phase, at the time of evaluation planning it was not systematized for all staff and did not include a goal-setting component. These characteristics of CAPE were considered, 
along with the interests of the author and the CAPE staff in planning an evaluation strategy. Despite the obstacles pertaining to the feasibility of outcome evaluation, the CAPE staff were very interested in client outcome information.

Through discussions with CAPE staff, a review of the literature on evaluations of employee assistance programs, and personal inquiries with directors of employee assistance programs around the country, a variety of questions emerged having to do with both process and outcome issues. The selection of a data-gathering method was based on considerations for how to most effectively address these questions. The clients who had been served by CAPE were considered the greatest source of information. An additional strategy considered was surveying superVisors of those employees who had been CAPE cllents. A purpose would be to directly gather data on possible changes in job performance after CAPE intervention. This option was dismissed, as the task of obtaining permission from employees to talk with their supervisors was considered too problematic. Tiurthermore, even if permission to talk with supervisors had been granted by employees, it was foreseeable that this process may have discouraged utilization of CAPE services by other employees. This strategy seemed a fertile source of information regarding the possible relationship between the provision of help for employee problems and their job performance. However, the importance of confidentiality and employee trust in the CAPE program far outwelghed the potential of this approach.

A review of the literature on client satisfaction studies indicated that existing client satisfaction measures were not sufficiently 
applicable to the CAPE program or the research questions formulated. Furthermore, while several employee assistance programs were identified that used a client feedback mechanism, each had designed survey forms specifically sulted to their program, client population, and evaluation interests. Consequently, to attempt to answer the questions raised for the research study, a multi-dimensional client satisfaction questionnaire was chosen as the most appropriate data-gathering instrument. The questionnaire was constructed to gather information from clients on both the dimensions of outcome and process.

\section{Focus and Objectives of the Study}

This section provides a sumary of the kinds of information that was sought in designing the client satisfaction questionnaire. The questions in the instrument reflect both the interests of the author and the CAPE staff. As mentioned previously, the questionnaire focused on both the dimensions of process and outcome. The process dimension refers to the steps involved in being a CAPE cllent, 1.e., obtaining and using CAPE services. The outcome dimension refers to the client's satisfaction with the end results and self-report of change attributable to CAPE services. The assessment of outcome is based on client perceptions. Such data is descriptive in nature, since the results are not to be compared to pre-established objectives, e.g., that " $X$ " percent of CAPE clients will be satisfled with services. However, it is implicitly understood by the author and CAPE staff that it is desirable for clients to be satisfied with thelr involvement with CAPE. Areas of process addressed in the questionnaire were: 
(1) Psychological accessibility and avallability of CAPE.

(2) Physical accessibility and accessibility of CAPE.

(3) Obstacles to utilization of CAPE services.

Areas of outcome addressed in the quest1onnaire were:

(1) Degree to which expectations of CAPE were met.

(2) Satisfaction with services or benefits obtained from going to CAPE.

(3) Assessment of changes in work performance attributable to receiving CAPE services.

In addition, the following information on client characteristics was sought:

(1) Previous experience seeing a mental health professional.

(2) The type of personal problem that led to seeking help.

(3) Personal comfort or discomfort in seeking help.

(4). Whether personal problems affected job performance.

The Data Collection Process

A mall-out questionnaire was chosen as the method of data collection. This method was selected because CAPE staff agreed on the desirability of having the study participant group as large as possible, and lack of time and financial resources precluded the collection of data by other means. It was decided to administer the questionnaire to all individuals who had been clients or were presently being seen at CAPE. Excluded from this target group were seven individuals who had had contact with CAPE on the telephone. Consequently, for purposes of this study only those individuals who had been seen at least once in person were defined as clients.

Several reasons led to this definition of the study population and the decision to not draw a sample. First, the literature suggested that it is difficult to obtain adequate response rates with mailed-out client satisfaction questionnaire (Attkisson, Hargreaves, Horowitz and 
Sorensen 1978). Attkisson, Hargreaves, Horowitz and Sorensen (1978) suggest that at least thirty to fifty returned questionnaires be the minimum for a client satisfaction study. To maximize the probability of reaching this minimal figure, all ninety-eight past and present clients were malled a copy of the questionnaire. Secondly, the CAPE staff were interested in specific sub-groups of the client population. Clients were employees at five different companies, and it was anticipated that useful information could be obtained from the analysis of data regarding, these sub-groups. This potential information was considered adjunctive, since the author will make it available to CAPE staff, but will not include it in the data analysis of this report. The next step in the evaluation process was to collect the data. The questionnaire was malled to the entire study group, along with a cover letter and a stamped reply envelope. A copy of the questionnatre and the cover letter are Included in appendix A. Each questionnaire was coded with a number, so that identity of respondents would be known. While the purpose of coding was not explained in the cover letter, the assurance of confidentiality was communicated. Coding had several purposes. First, demographic information already in the client records was planned to be used in the compilation of respondent and nonrespondent characteristics. Second, sub-grouping by company was considered to be of potential benefit in the data analysis. Coding was thus necessary to 1dentify from which companies the clients were employed. It. Is not known whether the coding affected the response rate. Questionnalres were sent to all ninety-eight individuals in the target population. Within two weeks thirty-nine questionnaires (40 
percent) had been received. Between two and three weeks after the mail-out, an effort was made to telephone each remaining nonrespondent to encourage participation in the survey. Of fifty-nine nonrespondents, a total of forty-two (71 percent) were reached; twenty-three of these (55 percent) eventually retumed completed questionnaires. In contrast, of the seventeen nonrespondents not reached by telephone, two (12 percent) eventually returned completed quéstionnaires. Four letters ( 4 percent) were eventually returned by the post office as undeliverable and address unknown. A response cut-off date was established four weeks after the mail-out. At this time, sixty-two completed questionnaires (63 percent) had been received. Of the ninety-four letters delivered by the post offlce, sixty-two questionnaires (66 percent) were recelved. 


\section{DATA ANALYSIS}

The first section in this chapter presents the characteristics of the ninety-eight subjects in the study population. This section also presents the characteristics of respondents and non-respondents, and a discussion of the differences. The second section discusses additional characteristics of the respondents, information which was derived from the questionnaire results. The third section presents the responses to the process-oriented items. The fourth section discusses the responses to the open-ended items on the questionnaire. A content analysis of the responses to the open-ended questions was done, responses not fitting the identified categories were included in the "other" category. The sixth section contains a discussion of the crosstabulations performed. Included in this final section are the results to cross-tabulations between respondent characteristics and selected questionnaire items and cross-tabulations between selected questionnaire items.

\section{Characteristics of the Study Population}

As can be seen from table I, the study population included sixtythree females ( 64 percent) and thirty-five males (36 percent). Fiftynine (60 percent) of the subjects were married or living with a partner, twenty (20 percent) were divorced or separated, and fifteen ( 15 percent) were single. Nineteen subjects (19 percent) were in the 18-24 (years 
old) category, thirty-six (37 percent) were in the 25-34 category, twenty (20 percent) were in the 35-44 category, and nineteen (19 percent) were in the $45-54$ category. As far as education level of the

\section{TABLE 1}

CHARACIERISTICS OF THE STUDY POPULATION

Sex:

ihale
Female

Total:

$\begin{array}{ll}35 & 36 \% \\ \frac{63}{98} & \frac{64}{100}\end{array}$

Marital status:

Married or Living Together

59

60

Divorced or Separated

20

20

Single

15

15

Widow or Widower

Missing Information

Total:

1

$\frac{3}{98}$

$\frac{3}{99 a}$

Age:

18-24

$25-34$

$35-44$

19

36

20

45-54

19

Missing Information

Total:

$\frac{4}{98}$

19

37

20

19

$\frac{4}{99}$

Education:

Non-HS Graduate

HS Graduate

Post HS Technical Training

Some College

Bachelor's Degree

Post-Graduate Degree

Missing Information

Total:

$\begin{array}{rr}7 & 7 \\ 32 & 33 \\ 13 & 13 \\ 15 & 15 \\ 15 & 15 \\ 9 & 9 \\ 7 & 7 \\ 98 & 99\end{array}$




\section{TABLE 1-Continued}

Characteristics

Number

Percent

Monthly Income:

500-799

800-1099

29

29

$30 \%$

1100-1399

20

30

1400-1699

1700-1999

Total:

Missing Information

Client Status:

Employee Only

Family Jlember Only

Total:

Employee and Family Member(s)

62

63

9

$\frac{27}{98}$

20

5
4

$\frac{11}{98}$

$\frac{11}{100}$

Involvement at Survey TIme:

Still in Progress

26

$\frac{72}{98}$

27

Case Closed

Total:

$\frac{73}{100}$

Number of Times Seen:

$1-2$

$3-10$

Over 10

Total:

35
56

$\frac{7}{98}$

36

57

$\frac{28}{100}$

arotals vary on this table and all following tables because of consistent rounding off to nearest whole number.

study population, seven (7 percent) were non-high school graduates, thirty-two (33 percent) were high school graduates, thirteen (13 percent) had recelved technical training, fifteen (15 percent) had some college education, fifteen (15 percent) had college degrees, and nine (9 percent) had post-graduate degrees. Regarding income characteristics of the study population, twenty-nine (30 percent) earmed \$500-799 per month, twenty-nine (30 percent) were in the \$800-1099 category, 
twenty (20 percent) were in the \$1100-1399 category, five (5 percent) were in the \$1400-1699 category, and four subjects (4 percent) were in the \$1700-1999 category. With regard to client status, sixty-two subjects (63 percent) were employees only, nine (9 percent) were family members of employees, and twenty-seven subjects (28 percent) were those clients defined as employee and family member(s). At the time the questionnaire was malled out, twenty-sfx (27 percent) of the subjects were active clients and seventy-two (73 percent) were clients whose cases had been closed. In looking at the number of times the subjects were seen at CAPE, the mean was 4.6, the median was 8 , the mode was 1 , and the range was 1 to 18 .

Two groups comprised the study population of ninety-eight subjects. There were sixty-two subjects in the group of persons who responded to the request to complete the questionnaire, hereafter referred to as the respondent group. There were thirty-six subjects in the group of persons who did not respond to the request to complete and return the questionnaire, hereafter referred to as the nonrespondent group. The characteristics of the respondent and nonrespondent groups are presented in table 2. This information was obtained from client records.

\section{Characteristics of the respondents}

As can be seen from table 2, fifteen respondents (24 percent) were male and forty-seven (76 percent) were female. Thirty-seven respondents (60 percent) were married or living with a partner, thirteen (21 percent) were divorced or separated, and ten (16 percent) were single. The sixty-two respondents were spread out among the age-group categories, with the 25-34 (years old) category having the most re- 
spondents, twenty-four (39 percent). As far as education, the respondents were also spread out among all categorles, ranging from three ( 5 percent) who were non-high school graduates to sixteen (26 percerit) who were high school graduates. In collapsing categories, twenty-one (34 percent) had some college or technical training after high school and twenty (32 percent) had collepe degrees. Twenty-two respondents (36 percent) were in the lowest income category (\$500-799), seventeen (27 percent) were in the \$800-1099 category, eleven (18 percent) were In the $\$ 1100-1399$ category, and six (10 percent) earmed over $\$ 1400$ per month.

Th1rty-flve respondents ( 57 percent) were individual employees of the companies in contract with CAPE. Twenty respondents (32 percent) were employees and family member(s), and seven ( 11 percent) were family

TABLE 2

CHARACTERTSTICS OF THE RESPONDENTS AID NONRESPONDENTS

Characteristics

Respondents

Nonrespondents

Sex: $:^{b}$

Male
Female

Total:

\begin{tabular}{llll}
15 & $(24 \%)$ & 20 & $(56 \%)$ \\
47 & $(76 \%)$ & 16 & $(44 \%)$ \\
\hline 62 & $\frac{100}{100}$ & $\frac{100}{100}$
\end{tabular}

Marital Status:

Married or Living Together

Divorced or Separated

Single

Widow or Widower

Total:

Missing Information

$\begin{array}{rrrr}37 & (60 \%) & 22 & (61 \%) \\ 13 & (21 \%) & 7 & (19 \%) \\ 10 & (16 \%) & 5 & (14 \%) \\ 1 & (2 \%) & 0 & (0 \%) \\ \frac{1}{62} & \frac{(2 \%)}{101} & \frac{2}{36} & \frac{(6 \%)}{100}\end{array}$


TABLE 2-Continued

Age :

Total:

$18-24$
$25-34$
$35-44$
$45-54$
Missing Information

Education:

Non-HS rraduate

HS Graduate

Post-IIS Technical Training

Some College

Bachelor's Degree

Post-graduate Derree

Missing Information

Total:

Monthly Income:

$\$ 500-799$

$\$ 800-1099$

$\$ 1100-1399$

$\$ 1400-1699$

\$1700-1999

Missing Information

Total:

Client Status:

Employee Only

Family Member Only

Employee and Family

Total:

Member(s)

Involvement at survey Time:

Total:

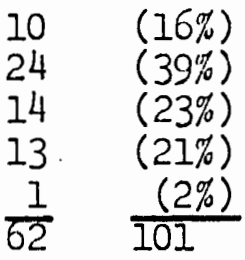

\begin{tabular}{rr}
3 & $(5 \%)$ \\
16 & $(26 \%)$ \\
9 & $(15 \%)$ \\
12 & $(19 \%)$ \\
12 & $(19 \%)$ \\
8 & $(13 \%)$ \\
2 & $(2 \%)$ \\
\hline 22 & $\frac{(29}{99}$
\end{tabular}

$4 \quad(11 \%)$

16 (44\%)

$4 \quad(4 \%)$

$3 \quad(8 \%)$

$3 \quad(8 \%)$

$1 \quad(3 \%)$

$\frac{5}{36} \quad \frac{(14 \%)}{99}$

$\begin{array}{rrrr}22 & (36 \%) & 7 & (19 \%) \\ 17 & (27 \%) & 12 & (33 \%) \\ 11 & (18 \%) & 9 & (25 \%) \\ 3 & (5 \%) & 2 & (6 \%) \\ 3 & (5 \%) & 1 & (3 \%) \\ 6 & (10 \%) & \frac{5}{36} & \frac{(14 \%)}{100}\end{array}$

$35 \quad(57 \%)$

27

$(75 \%)$

$(69 \%)$

$\frac{20}{62} \quad \frac{(32 \%)}{100}$

$\frac{7}{36} \quad \frac{(19 \%)}{100}$

$22 \quad(36 \%)$

$\frac{40}{62} \quad \frac{(65 \%)}{101}$
$4 \quad(11 \%)$

$\frac{32}{36} \quad \frac{(89 \%)}{100}$ 
Number of Times Seen:

$\begin{array}{ccccc}1-2 & 21 & (34 \%) & 14 & (39 \%) \\ 3-10 & 35 & (57 \%) & 21 & (58 \%) \\ \text { Over 10 } & 6 & (10 \%) & \frac{1}{61} & \frac{(3 \%)}{100} \\ \text { Total: } & \frac{6}{101} & \frac{30}{36} & \end{array}$

b Statistically significant: $x^{2}=9.76 ; d f=1 ; p .<.01$.

members only, i.e., the employee of the CAPE-contracted company was not involved.

At the time of the survey, forty respondents (69 percent) had been terminated, while twenty-two (35 percent) were still being, seen at CAPE. In looking at the number of times the respondents were seen, the mean was 5.5 , the median was 7.5 , the mode was 2 , and the range was $1-18$.

Characteristics of nonrespondents

Twenty of the nonrespondents (56 percent) were male and sixteen (44 percent) were female. Twenty-two of the nonrespondents (61 percent) were marrled or living with a partner, seven (19 percent) were divorced or separated, and flve (14 percent) were single. In looking at the age of nonrespondents, nine (25 percent) were in the 18-24 (years old) category, twelve (33 percent) were in the 24-34 category, six (17 percent) were in the 35-44 category, and six (17 percent) were also in the 45-54 category.

As far as the education level of the nonrespondents, four (11 percent) were non-high school graduates, sixteen (44 percent) were high 
school graduates, seven (19 percent) had some college or technical training after high school, and four (II percent) had college degrees. Seven nonrespondents (19 percent) were in the lowest income category (\$500-799), twelve (33 percent) were in the \$800-1099 category, nine (25 percent) were in the \$1100-1399 category, and three nonrespondents ( 9 percent) earned over $\$ 1400$ per month. Examination of the cllent status of the nonrespondents reveals that twenty-seven (75 percent) were employees only, two ( 6 percent) were family members of employees, and seven (19 percent) were clients defined as employee and family member(s). Regarding the involvement of nomrespondents at the time of the survey, four ( 11 percent) were open cases and thirty-two (89 percent) were closed cases. $\Lambda \mathrm{s}$ far as the number of times the nonrespondents were seen, the mean was 3.8 , the median was 5.5 , the mode was 1 , and the range was 1 to 13 .

Discussion of differences between respondents and nonrespondents

In looking at the characteristic of sex, the respondent group was more similar to the total study population than the nonrespondent group. Thirty-five males ( 36 percent) composed the study population and fifteen males (24 percent) composed the respondent group, while twenty males (56 percent) were in the nonrespondent Eroup. A chi square test utilizing contingency tables indicated a statistically significant difference between respondents and nonrespondents as to their sex.

Collapsinf; of data would have been necessary to perform a statistical analysis on the other characteristics. In reviewing the data on the characteristics of the respondents and nonrespondents, it was con- 
cluded that such a procedure would have resulted in a loss of specific information, so no further statistical analyses were done. However, in reviewing the information on subject characteristics, some suggestive comments can be put forth. The study population group, the respondent group, and the nonrespondent group were very similar as far as distributions regarding marital status, income, and age.

There was a strong tendency for those subjects with the most education to be in the respondent group. Of the twenty-four subjects who had at least a college degree, twenty responded to the questionnaire and four did not. There was also a tendency for those subjects who were clients defined as the employee and fanily member(s) to be in the respondent group rather than the nonrespondent group. Of the twentyseven subjects so classified, twenty were respondents and seven were nonrespondents. There was a simflar tendency when looking at the subjects' involverent with CAPE at the time of the survey. Of the twentys1x subjects whose cases were still in progress, twenty-two were respondents, and four were nonrespondents.

There was a tendency for those subjects who were seen the most number of times to be respondents rather than nonrespondents. Those subjects in the respondent group were seen an average of 5.5 times, as compared to nonrespondents who were seen an average of 3.8 times. There was also a slight tendency for those subjects in the respondent group to be seen more often as compared to the total study population, mean $=5.5$ and 4.6 , respectively.

Additional Characteristics of the Respondents

This section will present information on the characteristics of 
the respondents that was obtained from the questionnaire. The results from respondents are included in table 3.

Twenty-six respondents ( 42 percent) reported previously having seen a mental health professional and thirty-six (58 percent) had never previously sought professional help. A mental health professional was defined as a social worker, psycholomist, psychiatrist, or counselor. The major issues bringing individuals to CAPE were family or marital problems and psychological or emotional difficulties. The instructions for completing this 1tem on the questionnaire asked the subject to indicate the primary problem that led to their coming to CAPE. Twelve respondents indicated more than one primary problem. In these cases the author reviewed the client's initial intake form and used the client's autoblographical statement as a basis for deciding what seemed the primary area of difficulty. This procedure did result in a loss of Information, even though with most cases it was possible to make a decision on what appeared to be the primary reason for seeking help. After this re-assessment of the data, it was found that twenty-nine respondents (47 percent) soupint services because of psychological or emotional difficulties. Twenty-five respondents (40 percent) sought services because of famtly or marital problems. Seven respondents (II percent) reported work-related problems as their primary reason for seeking assistance. Work-related problems included impalrment of work performance, conflicts with fellow employees or an employer, and dissatisfaction with one's job. Only one respondent (2 percent) reported an alcohol problem as the primary reason for seeking help.

Respondents were almost evenly divided on whether their work 
TABLE 3

ADDITIONAL CIARACTERISTICS OF THE RESPONDENTS

Characteristics

Number

Percent

Previous Contact with a liental

Health Professionals:

Yes

No

Total:

$\begin{array}{ll}26 & 42 \% \\ \frac{36}{62} & \frac{58}{100}\end{array}$

Issues Which Brought Client(s)

to CAPE:

Psychological or Emotional

Alcohol

Work-related

Family or Marital

Total:

\begin{tabular}{rr}
29 & 47 \\
1 & 2 \\
7 & 11 \\
25 & 40 \\
\hline 62 & 100
\end{tabular}

Was Work Performance Affected

by Personal Difficulties:

Yes

22

36

Not Sure

No

Total:

18

29

$\frac{22}{62}$

$\frac{36}{101}$

How Work Performance Was Affected:

Mussed Work

Decreased Production

Decreased Concentration

Decreased Ability to Work With Others

Physical Distress

Psychological Distress

Total:

Blank

\begin{tabular}{rr}
4 & 7 \\
2 & 3 \\
4 & 7 \\
2 & 3 \\
3 & 5 \\
5 & 8 \\
42 & $\frac{68}{62}$ \\
\hline 101
\end{tabular}

performance was affected by the personal difficulties they were experlencing, 'Twenty-two respondents (36 percent) reported their work performance had been affected, twenty-two ( 36 percent) also said their work performance was not affected, and elghteen respondents (29 percent) indicated they were unsure if their work performance had been 
affected by their personal difficulties.

As a follow-up question to the above, subjects were asked to indicate how thelr work performance was affected by their personal problems. Twenty respondents ( 32 percent) answered this question, and these were the same respondents who had indicated on the previous item that their work had been affected by their personal problems. Of those answering this question, four (20 percent) reported missing work, two (10 percent) reported their production rate was decreased, four (20 percent) mentioned decreased concentration, and two (10 percent) reported a decreased ability to work with others. Eight respondents (40 percent) mentioned various symptoms that were categorized as physical or psychological distress.

Responses to Process-oriented Items

Question number one was, "Before your contact with CAPE, what was your personal attitude toward CAPE?" Thirty-three respondents (53 percent) indicated a definitely or somewhat positive attitude, twenty-six respondents ( 42 percent) Indicated having no opinion, and three respondents ( 5 percent) reported having a definitely or somewhat negative attitude prior to contact with CAPE.

Question number two was, "From what source did you hear about the CAPE program?" As can be seen in table 4, respondents heard about CAPE in a variety of ways. Twenty respondents (32 percent) indicated hearing about CAPE from their company personnel department, while sixteen respondents (26 percent) heard of CAPE from publicity or CAPE staff. 
TABLE 4

CLIFNTS' INFORNATION SOURCE IREGARDING CAPE

Source

Publicity

CAPE Staff

Fellow Employees

Personnel Department

Supervisor

Family Member

Other

Total:

Number

Percent

question number four was, "How comfortable were you seeking help for personal problems?" Forty-two respondents (68 percent) indicated being very or somewhat comfortable, while twenty ( 32 percent) indicated belng very or somewhat uncomfortable seeking help.

Question number elght was, "Once you called CAPE for an appointment, how long was it before you were seen?" As can be seen from table 5, sixty respondents (97 percent) reported being seen within six days.

\section{TABLE 5}

CLIENTS' REPORT OF WAITING TIME

Number of Days

Number

Percent

Seen Same Day

1-2 Days

1

3-4 Days

4-6 Days

13
3
7.

$21 \%$

20

10

16

$\frac{3}{62}$

$\frac{5}{100}$ 
Question number nine was, "Was this soon enough for you?" Sixty respondents (97 percent) indicated they were seen soon enough, while two respondents ( 3 percent) Indicated they did not feel they were seen soon enough.

Question number ten was, "What was the total number of times you were seen by a CAPE staff?" Twenty-one respondents (34 percent) were seen one or two times, thirty-five respondents (57 percent) were seen three to ten times, and six (10 percent) were seen more than ten times. The average number of times seen for the sixty-two respondents was 5.5.

Question number eleven was, "Was this enough for you?" Fortyeight respondents (77 percent) indicated satisfaction with the number of times seen, while fourteen (23 percent) were not satisfied with the number of times seen.

Question number thirteen was, "If CAPE had not been avaliable, would you have sought help elsewhere from a mental health professional?" Twenty-two respondents (36 percent) indicated they would have sought help elsewhere, twenty-two (36 percent) also indicated they did not know if they would have, and eighteen respondents (29 percent) Indicated they would not have sought help elsewhere.

\section{Responses to Outcome-oriented Items}

Question number twelve was, "Did you get what you expected from going to CAPE?" Twenty-five respondents ( 40 percent) indicated their expectations were definitely met, twenty-nine respondents (47 percent) reported somewhat, and eight respondents (13 percent) sald their expectations were definitely not met.

Question number fourteen was, "In an overall sense, how satisfied 
are you with the services you recelved from CAPE?" Fifty-three respondents ( 86 percent) indicated being very or milaly satisfied, while nine ( 15 percent) indicated being very or milaly dissatisfied with services received from CAPE.

Question number fifteen was, "If you were to seek help again, would you return to CAPE?" Forty-four respondents (71 percent) said they would return, fourteen (23 percent) indicated they were not sure, and four ( 6 percent) reported they would not return.

Question number sixteen was, "As a result of seeing a CAPE counselor, was there a change in your work performance?" Twenty-one respondents ( 34 percent) indicated improvement, forty (65 percent) reported no change, and one respondent (2 percent) indicated their work performance got worse.

\section{Responses to Open-ended Iterns}

A preliminary question to the open-ended 1tems was, "Do you know fellow employees who might benefit from the services at CAPE, but don't go?" Thirty-four respondents (56 percent) indicated awareness of fellow employees who could benefit from services but do not go, while twenty-eight (45 percent) reported not knowing of fellow employees in need of services.

Question number elghteen was, "If yes to number seventeen, what do you think might be making it hard for them to go?" Thirty-eight (61 percent) of the sixty-two respondents answered this question. As can be seen from table 6 , eleven ( 30 percent) thought the stigma of mental health problems was making it hard for fellow employees who might benefit from CAPE services to seek services. Elght (2I percent) 
thought the stigma of seelng a professional, and elght (2l percent) thought the failure to recognize mental health problems was contributory to the failure of possibly troubled employees to seek CAPE services.

TABLE 6

CLIENTS' REPORT OF OBSTACLES TOR FELLOW EVIPLOYEES

Comments

Number

Percent

Stigma of Mental Health Problems

Stigma of Seeing, a Mental Health Professional

Failure to Recognize Mental Health Problems

Insufficient Understanding of Assistance Available

Total:

Other

Question number nineteen was, "What do you think would need to change at your place of employment for more people to use CAPE services?" As can be seen from table 7, nineteen respondents (31 percent) suggested increased publicity of CAPE as a way to increase the number of employees who would use CAPE services.

\section{TALIE 7}

CLIENTS' SUGGISSTIONS FOR CHANGES AT WORK-SITE

Percent 
TABLE 7--Continued

Suggestions

Number

Percent

Information on Mental Health Problems and Counseling

Don't know

Blank

Total:

Others

\begin{tabular}{rr}
6 & $10 \%$ \\
5 & 8 \\
13 & 21 \\
13 & 21 \\
\hline 52 & $\frac{21}{101}$
\end{tabular}

Question number twenty was, "What do you think would need to change about CAPE for more people to use CAPE services?" As can be seen from table 8, fifteen respondents (24 percent) suggested increasing publicity of CAPE services as a way to increase the number of employees utilizing CAPE services. Elght respondents ( 13 percent) commented that there was no need for CAPE to change.

TABLE 8

CLIENIS' SUGGESTIONS FOR CHANGES AT CAPE

Suggestions

Number

Percent

Increased Avallability and Accessibility

Publicity of CAPE Services

Provide More Services

No Need to Change

Blank

Others

Total:

\begin{tabular}{rc}
6 & $10 \%$ \\
15 & 24 \\
4 & 7 \\
8 & 13 \\
21 & 34 \\
8 & 13 \\
\hline 62 & $\frac{13}{101}$
\end{tabular}

Question number twenty-one was, "Any comments or suggestions about your experiences with CAPE?" As can be seen from table 9, thirtyone respondents (50 percent) made positive comments about their ex- 
perience with CAPE, while eight respondents (13 percent) made negative comments, and only three respondents ( 5 percent) indicated suggestions for change.

TABLE 9

CLIENT'S' COM.ENTS OR SUGGESTIONS

Comments

Number

Percent

Appreciation of Help

Positive Comments Regarding Staff

Negative Comments Regarding Staff

Appreciative of Services Existence

Criticisms of Services

Miscellaneous Suggestions for Change

Blank

Total:

$\begin{array}{rr}15 & 24 \% \\ 11 & 18 \\ 5 & 8 \\ 5 & 8 \\ 3 & 5 \\ 3 & 5 \\ 20 & \frac{32}{62} \\ \frac{100}{62}\end{array}$

Results and Discussion of Cross-tabulations.

In this section the results of the cross-tabulations which were done will be examined. Some collapsing of categories was done to compensate for the dispersion of responses to some of the questionnaire items. It is possible that the small study population contributed to the lack of statistically significant differences with most of the cross-tablulations. No further attempt was made to statistically analyze the results, as the raw data was, for the most part, judged inappropriate for further analyses.

When the characteristic of sex was compared with nine selected questionnaire items, no statistically significant differences were found. While no cross-tabulations were significant at the 5\% level, several comparisons suggested tendencles toward differences. As can 
be seen from table 10, there was a tendency for those respondents seen 1-2 times to be female. Of the twenty-one respondents seen 1-2 times, 40 percent of the females (19) and 13 percent of the males (2) were in this category.

There seemed to be a tendency for females to be less satisfied than males with the number of times seen. As can be seen from table 11 , 26 percent of the forty-seven female respondents (12) as compared to 13 percent of the fifteen males (2) Indicated dissatisfaction with the number of times seen.

As can be seen from table 12, 93 percent of the males (14) and 85 percent of the females (40) sald that their expectations of CAPE were definitely or somewhat met. Seven percent of the males (1) and 15 percent of the females (7) indicated not getting what they expected from

TABLE 10

SEX BY NUMBER OF SESSIONS

1-2 3-10 Over $10 \quad$ Row Total

Sex:

$\begin{array}{ccccc}\text { Male } & 2(13 \%) & 12(80 \%) & 1(7 \%) & 15(100 \%) \\ \text { Female } & 19(40 \%) & 23(49 \%) & \frac{5(11 \%)}{6} & \frac{47(100 \%)}{62}\end{array}$


TABLE 11

SEX BY SATISFACTION WITH NUMBER OF SESSIONS

Yes

No

Row Total

Sex:

Male

Female

Colum Total

$13(87 \%)$

$35(74 \%)$

$\frac{2(13 \%)}{12(26 \%)}$

$15(100 \%)$

$47(100 \%)$

TABLE 12

SEX BY WHETHER EXPECTATIONS WERE NET

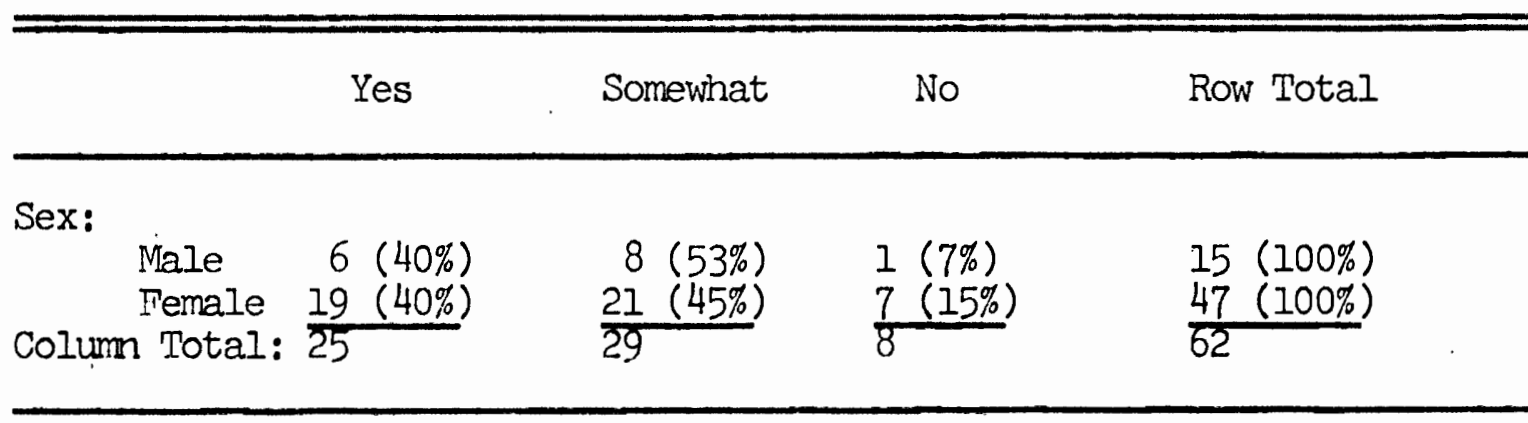

CAPE.

The sex of respondents was also compared with the item asking whether they would have sought help elsewhere if CAPE had not been available. From table 13 it can be seen that 40 percent of the females (19) and 20 percent of the males (3) answered in the affirmative. As can be seen. from table 14, 93 percent of the males (14) and 83 percent of the females (39) reported overall satisfaction with services recelved from CAPE.

The results of the four remaining cross-tabulations of sex with questionnaire items are included in appendix $B$. These results are not discussed, since no tendencies toward differences are suggested. 
One of the reasons for comparing level of education with nine of the questionnaire items was the expectation that less educated clients would differ in their responses from more educated clients. While there were some proclivities in that direction, none of the results was statistically significant.

As can be seen from table 15, there was a tendency for those respondents with previous counseling experience to also have the most education. Fifty-flve percent (II) of those with at least a Bachelor's degree indicated previous counseling as compared to 26 percent (5) of those with high school or less education. From table 16 it can be seen that those who reported they would have sought help elsewhere tended to be in the higher education categories.

TABLE 13

SEX BY WOULD SEEK HELP ELSEWHERE

Yes Don't know No Row Total

Sex:

Male $3(20 \%)$ $\begin{array}{r}7(47 \%) \\ 15(32 \%) \\ \hline 22\end{array}$ $\begin{array}{r}5(33 \%) \\ 13(28 \%) \\ \hline 18\end{array}$ $15(100 \%)$ Female Colum Total: $\frac{19(40 \%)}{22}$ 
TABLE 14

SEX BY OVERALU SATISFACTION WITH CAPE

Satisfied

Dissatisfied

Row Total

Sex:

\begin{tabular}{clll} 
Male & $14(93 \%)$ & $1(7 \%)$ & $15(100 \%)$ \\
Female & $39(83 \%)$ & $8(17 \%)$ & $47(100 \%)$ \\
Column Total: & 53 & 9 & 62 \\
\hline
\end{tabular}

TABLE 15

EDUCATION BY PREVIOUS COUNSELING EXPERIENCE

Yes No Row Total

Education:
HS or Less
Technical Training or Some College
BA, MA, Ph.D.

$\begin{array}{r}5(26 \%) \\ 9(43 \%) \\ 11(55 \%) \\ \hline 25\end{array}$
$14(74 \%)$
$19(100 \%)$
$21(100 \%)$
$\begin{array}{r}12(57 \%) \\ 9(45 \%) \\ \hline 35\end{array}$
$\frac{20(100 \%)}{60}$

Column Total

TABLE 16

EDUCATION BY WOUTD SEEK HELP ELSEWHERE

\begin{tabular}{|c|c|c|c|c|}
\hline & Yes & Unsure & No & Row Total \\
\hline $\begin{array}{l}\text { Education: } \\
\text { HS or Less } \\
\text { Technical Training } \\
\text { or Some College } \\
\text { BA, MA, Ph.D. } \\
\text { Colum Total }\end{array}$ & $\begin{array}{r}3(16 \%) \\
11(52 \%) \\
8(40 \%) \\
22\end{array}$ & $\begin{array}{r}7(37 \%) \\
5(24 \%) \\
9(45 \%) \\
21\end{array}$ & $\begin{array}{r}5(24 \%) \\
3(15 \%) \\
17\end{array}$ & $\begin{array}{l}19(100 \%) \\
21(100 \%) \\
20(100 \%) \\
60\end{array}$ \\
\hline
\end{tabular}

Forty percent (8) of those with a college degree, 52 percent (11) of 
those with technical training or some college, and 16 percent (3) of those with high school or less education reported they would have sought help elsewhere if CAPE had not been available.

The cross-tabulations of education levels with the items regarding satisfaction revealed very similar distributions of responses, 1.e., those with the least amount of education were as likely to be satisfled with services as those with the most education. The results to these cross-tabulations are included in appendix $\mathrm{C}$.

Income levels were also compared to the same questionnalre items as with education levels. Again there were no statistically significant differences, but several tendencies can be 1dentifled. In looking at table 17 a tendency can be seen for those respondents in the lower income groups to report feeling uncomfortable, as compared to those in the higher income levels. Forty-one percent (9) of those earning $\$ 500$ 799 were uncomfortable, as compared to elghteen percent (4) of those eaming more than $\$ 1100$ per month. As can be seen from table 18 , there was a slight tendency for the lower income respondents $(\$ 500-1100)$ to report they would not have sought help elsewhere, as compared to the higher income (over $\$ 1100$ ) respondents. Forty-seven percent (8) of those earning over $\$ 1100$ versus 33 percent (13) of those earning; $\$ 500$ 1100 indicated they would have sought help elsewhere if CAPE had not been available.

The cross-tabulations of income level with items regarding satisfaction revealed very similar distributions of responses, 1.e., lower income clients were as likely to be satisfled with services as higher income clients. The results of these cross-tabulations are included 
TABLE 17

INCOME BY COMFORT SEEKTING HELP

Comfortable Uncomfortable Row Total

Income:

$\begin{array}{rrrr}500-799 & 13(59 \%) & 9(41 \%) & 22(100 \%) \\ 800-1099 & 13(76 \%) & 4(24 \%) & 17(100 \%) \\ 1100-1399 & 10(91 \%) & 1(9 \%) & 11(100 \%) \\ 1400-1999 & 3(50 \%) & 3(50 \%) & 6(100 \%) \\ \text { Column Total: } & 39 & 17 & 56\end{array}$

TABLE 18

INCOME BY WOULD SEEK HELP ELSEWHERE

\begin{tabular}{ccccc}
\hline & Yes & Unsure & No & Row Total \\
\hline Income: & & & & \\
$500-799$ & $7(32 \%)$ & $9(41 \%)$ & $6(27 \%)$ & $22(100 \%)$ \\
$800-1099$ & $6(35 \%)$ & $3(18 \%)$ & $8(47 \%)$ & $17(100 \%)$ \\
$1100-1399$ & $5(45 \%)$ & $3(27 \%)$ & $3(27 \%)$ & $11(99 \%)$ \\
I 1400-1999 & $\frac{3(50 \%)}{31}$ & $\frac{3(50 \%)}{18}$ & $\frac{0(0 \%)}{17}$ & $\frac{6}{56}$ \\
Column Total & $2100 \%)$ \\
\hline
\end{tabular}

In appendix D.

The primary presenting problems of respondents were compared to selected questionnalre 1tems. Again no statistically slgnificant differences were found. As can be seen from table 19, there might be a tendency for those with alcohol or work-related problems to indicate they would not have sought help elsewhere if CAPE had not been available.

Table 20 presents the results of comparisons when the categories of alcohol and work-related problems are combined, and when psycho- 
TABLE 19

PRESENIING PROBLEM BY WOULD SEEK HELP ELSEWHERE

Yes

Unsure

No

Row Total

Presenting Problems:

$\begin{array}{lrrrr}\begin{array}{l}\text { Psychological } \\ \text { Alcohol }\end{array} & 10(34 \%) & 13(45 \%) & 6(21 \%) & 29(100 \%) \\ \text { Work-related } & 0(0 \%) & 0(0 \%) & 1(100 \%) & 1(100 \%) \\ \text { Marital or } & 1(14 \%) & 1(14 \%) & 5(72 \%) & 7(100 \%) \\ \begin{array}{l}\text { Famlly } \\ \text { Total: }\end{array} & \frac{11(44 \%)}{22} & \frac{8(32 \%)}{22} & \frac{6(24 \%)}{18} & \frac{25(100 \%)}{62}\end{array}$

Colum Total:

logical and marttal or family problems are combined. As can be seen from table 20, 75 percent (6) of the eight respondents with alcohol or work-related problems indicated they would not have sought help elsewhere. This is as compared to 22 percent (12) of the fifty-four respondents with psychological and marital or family problems who reported they would not have sourht help elsewhere if CA.PE had not been available. The results of cross-tabulations of respondents' presenting problems. with items regarding satisfaction revealed similar distributions of responses. Tables of these results are included in appendix E. 
TABLE 20

PRESENTING PROBLEMS BY WOULD SEEK HELP ELSEWHERE

Yes Unsure No Row Total

Presenting Problems:

Alcohol and Work-related

Psychological and

$1(13 \%)$

$1(13 \%)$

$6(75 \%)$

$8(101 \%)$

Marital or

Family

Colum Total

$\frac{21(39 \%)}{22}$

$\frac{21(39 \%)}{22}$

$\frac{12(22 \%)}{20} \quad \frac{54(100 \%)}{62}$

The remainder of this section will discuss the results of crosstabulations between selected questionnaire items.

Question number one, which asked subjects to indicate their precontact attitude toward CAPE, was compared to several other 1tems. As can be seen from table 21,82 percent (27) of those with a positive attitude reported feeling comfortable seeking help. This is in comparison to the 52 percent (15) of the twenty-nine respondents with either no opinion or a negative opinion of CAPE who reported feeling comfortable.

From table 22 a tendency can be seen for those who had a positive attitude to report getting what they expected, as compared to those who had no opinion or a negative attitude. Fifty-eight percent (19) of those with a positive attitude and 23 percent (6) of those with no opinion reported getting what they expected from CAPE. There also was a tendency for those respondents with a positive pre-contact attitude to indicate they would return, as compared to those with no opinion or a negative attitude. As can be seen from table 23, 82 percent (27) of 
those with a positive attitude and 59 percent (16) of the twenty-nine with no opinion or a negative attitude indicated they would return to CAPE.

TABLE 21

PRE-CONTACT ATTITUDE BY CONFORT SEEKING HELP

Comfortable Uncomfortable Row Total

Pre-contact Attitude:

Positive

No Opinion

Negative

Column Total:
$27(82 \%)$

$14(54 \%)$

$1(33 \%)$
$33(100 \%)$
$26(100 \%)$
$3(100 \%)$
62

\section{TABLE 22}

PRE-CONTACT ATTITUDE BY WHETHER EXPECTATIONS WERE MET

Yes Somewhat No Row Total

Pre-contact Attitude:

\begin{abstract}
Positive
No Opinion

Negative
\end{abstract}

Colum Total

\begin{tabular}{rrrr}
$19(58 \%)$ & $12(36 \%)$ \\
$6(23 \%)$ & $14(54 \%)$ \\
$0(0 \%)$ & $3(100 \%)$ \\
\hline 25 & & 29
\end{tabular}

$\begin{array}{ll}2 & (6 \%) \\ 6 & (23 \%)\end{array}$

$0 \quad(0 \%)$

$33(100 \%)$
$26(100 \%)$
$3(100 \%)$
62 
TABLE 23

PRE-CONTACT ATT'ITUDE BY WOULD RETURN TO CAPE

Yes

No

Row Total

Pre-contact Attitude:

Positive

No Opinion

Negative

Column Total:

$27(82 \%)$

$14(54 \%)$

$\frac{2(67 \%)}{43}$

$6(18 \%)$

$33(100 \%)$

$12(46 \%)$

$\frac{1(33 \%)}{19}$

$26(100 \%)$

$\frac{3(100 \%)}{62}$

Cross-tabulations were also done between pre-contact attitude and previous counseling experience and satisfaction with services. These results are not suggestive of any differences. Tables of these results are included in appendix F.

Question number three, which asked subjects to indicate if they previously had seen a mental health professional, was compared with three other questionnaire 1tems. From table 24 it can be seen that there was a slight tendency for those respondents who had had previous counseling experience to report being comfortable seeking help, as compared to those without such experience. Seventy-three percent (19) of those with previous experience and 64 percent (23) of those without counseling experience indicated being comfortable seeking help.

From table 25 it can be seen that previous counseling experience seemed to make no difference in how respondents reported whether their expectations of CAPE were met. Similarly, in looking at table 26 it can be seen that previous counseling experience did not seem to make a difference in how respondents reported overall satisfaction with CAPE services. These results were contrary to the expectation that previous 
counseling experience would affect satisfaction with services.

\section{TABLE 24}

PREVIOUS COUNSELING BY COMFORT SEEKING HELP

Comfortable Uncomfortable Row Total

$\begin{array}{llrl}\begin{array}{c}\text { Previous Counseling: } \\ \text { Yes }\end{array} & 19(73 \%) & 7(27 \%) & 26(100 \%) \\ \text { No } & 23(64 \%) & 13(36 \%) & \frac{36(100 \%)}{62}\end{array}$

TABLE 25

PREVIOUS COUNSELING BY WHETHER EXPECTATIONS WERE MET

Yes Somewhat No Row Total

Previous Counseling:

$\begin{array}{cllll}\text { Yes } & 10(38 \%) & 13(50 \%) & 3(12 \%) & 26(100 \%) \\ \text { No } & 15(42 \%) & 16(44 \%) & 5(14 \%) & \frac{36(100 \%)}{62}\end{array}$

TABIE 26

PREVIOUS COUNSELING BY OVERATI SATISTACTION WITH SIRVICES

Satisfied Dissatisfied Row Total

Previous Counseling:

$\begin{array}{ll}\text { Yes } & 24(92 \%) \\ \text { No } & 29(81 \%)\end{array}$

Colum Total

53

\begin{tabular}{ll}
$2(8 \%)$ \\
$7(19 \%)$ \\
\hline 9
\end{tabular}

$\frac{26(100 \%)}{36(100 \%)}$

Question number four, which asked subjects to indicate their level of comfort seeking help for personal problems, was compared with three 
other questionnaire items. The results indicated no differences between the group that reported feeling comfortable and the group reporting feeling uncomfortable as far as responses to the three questionnalre 1tems. The results of these comparisons are included in appendix $G$. Again the results were contrary to the author's expectation that level of comfort in seeking help would affect report of satisfaction with services.

Question number six, which asked subjects if their personal difficulties were affecting their work performance, was compared to the responses to the item asking if work performance had changed as a result of CAPE services. The author's expectation was that those clients whose work performance had been affected by personal problems would report improvement in work performance after going to CAPE. The results to this inter-item comparison suggest such a relationship. As can be seen from table 27, 68 percent (15) of the twenty-two respondents who indicated Impalred work performance reported improved work performance attributable to CAPE services. Of the elghteen respondents who were unsure if their work performance had been affected, 22 percent (4) reported improved work performance and 78 percent (14) indicated no change in their work performance. Of the twenty-two who reported their work performance had not been affected by their personal problems, 91 percent (20) reported no change and 9 percent (2) indicated improved work performance as a result of going to $\mathrm{CAPE}$. The consistency in responses to these two items is suggestive of positive inter-item reliability. 
TABLE 27

WORK PERFORMANCE INIPAIRIENT BY CHANGE IN WORK PERFORMANCE

Improvement No Change Got Worse Row Total

Impairment:
Yes.

Not Sure

$15(68 \%)$

No

Column Total:

$4(22 \%)$

$2 \quad(9 \%)$

$6(27 \%)$
$14(78 \%)$
$20(91 \%)$
40

$1(5 \%)$

$0(0 \%)$

$\frac{0(0 \%)}{1}$

$22(100 \%)$

$18(100 \%)$

$\frac{22(100 \%)}{62}$

The number of times respondents were seen was compared to the report of satisfaction with number of sessions. It was expected that clients seen 1-2 times would not be as satisfied as compared to those seen a greater number of times. The results do not support this expectation. As can be seen from table 28 , of the twenty-one respondents seen 1-2 times, 81 percent (17) were satisfied with the number of sessions. Thirty-flve respondents were seen 3-10 times, and 74 percent (26) were satisfied with the number of sessions. SIx respondents were seen over ten times, and 83 percent (5) were satisfied with the number of sessions.

TABIE 28

NUMBER OF SESSIONS BY SATISFACTION WITH NUIBER OF SESSIONS

Satisfaction

Dissatisfaction

Row Total

Number of Sessions:

$\begin{array}{ll}1-2 & 17(81 \%) \\ 3-10 & 26(74 \%) \\ \text { Over 10 } & 5(93 \%) \\ \text { Total: } & 48\end{array}$

$4(19 \%)$
$9(26 \%)$
$1(17 \%)$
14

$21(100 \%)$

$35(100 \%)$

$6(100 \%)$

Colum Total: 
The number of times respondents were seen was also compared to the overall satisfaction with services at CAPE. Again it was expected that those seen 1-2 times would not be as satisfied as compared to those respondents seen a greater number of times. The results are indicative of only a slight tendency in that direction. As can be seen from table 29, of the twenty-one respondents seen 1-2 times, 76 percent (16) reported overall satisfaction with services. Of the thirty-five respondents seen 3-10 times, 89 percent (31) were satisfied with services. And of the six respondents seen over ten times, 100\% (6) reported overall satisfaction with services.

TABLE 29

NUMBER OF SFSSIONS BY OVERAIL SATISFACTION WITH SERVICES

Satisfaction Dissatisfaction Row Total

Number of Sessions:

$\begin{array}{cccc}1-2 & 16(76 \%) & 5(24 \%) & 21(100 \%) \\ 3-10 & 31(89 \%) & 4(11 \%) & 35(100 \%) \\ \text { Over 10 } & 6(100 \%) & 0(0 \%) & 6(100 \%) \\ \text { Colum Total: } & 53 & \frac{0}{92}\end{array}$

The involvement of clients with CAPE at the time of the survey was compared with the responses to three questionnaire items. Table 30 presents the results of the comparison between client involvement and whether expectations were met. Of the forty respondents whose cases were closed, 85 percent (34) reported their expectations of CAPE were somewhat or definitely met. Of the twenty respondents whose cases were st1Il open at the time of. the survey, 91 percent (20) indicated their expectations were somewhat or definitely met. Whether a respondent's 
case was open or closed at the time of the survey did not seem to affect the report of the degree to which expectations of CAPE were met.

TABLE 30

CLIENT INVOLVENENT BY WIETHER EXPECTATIONS WERE MET

Yes Somewhat No Row Total

Client Involvement:

$\begin{array}{cclll}\text { Open Case } & 9(41 \%) & 11(50 \%) & 2(9 \%) & 22(100 \%) \\ \text { Closed Case } & 16(40 \%) & 18(45 \%) & 6(15 \%) & 40(100 \%) \\ \text { Colum Total: } & 25 & 29 & \frac{8}{62}\end{array}$

The involvement of clients with CAPE was compared with the responses regarding overall satisfaction with services. The results of this comparison are presented in table 31. Of the forty respondents whose cases were closed at the time of the survey, 85 percent (34) indicated satisfaction with services and 15 percent (6) reported overall dissatisfaction with services. Of the twenty-two respondents whose cases were closed at the time of the survey, 82 percent (18) indicated satisfaction with services and 18 percent (4) reported overall dissatisfaction with services. Again the group of respondents whose cases were closed and those who were open responded similariy to this report of satisfaction. 
TABLE 31

CLIENT INVOLVEMENT BY OVERALI SATISFACTION WITH SERVICES

Satisfled Dissatisfled Row Total

Client Involvement:

Open Case

Closed Case

Colum Total:

$18(82 \%)$
$\frac{34 \cdot(85 \%)}{52}$

$4(18 \%)$
$6(15 \%)$
10

$22(100 \%)$

$40(100 \%)$

The Involvement of cllents was also compared with the responses to the question asking if they would return to CAPE if in need of help in the future. The results of this comparison are presented in table 32. Of the forty respondents whose cases were closed, 65 percent (26) sald they would return. Twenty-five percent (10) sald they were unsure and 10 percent (4) sald they would not return. Of the twenty-two respondents whose cases were open at the time of the survey, 82 percent (18) said they would return and 18 percent (4) indicated they were unsure.

\section{TABLE 32}

CLIENT INVOLVENENT BY WOULD RETURN TO CAPE

Yes Unsure No Row Total

Client Involvement:

Open Case

Closed Case

Column Total:
$18(82 \%)$

$\frac{76(65 \%)}{44} \quad \frac{10(25 \%)}{14}$
$0(0 \%)$

$4(10 \%)$
$22(100 \%)$

$40(100 \%)$ 
CONCLUSIONS AIN RECOMMENDATIONS

This chapter discusses the characteristics of the study group, the questionnaire results, and the implications of the study. In addition, an analysis of the response rate, a critique of the evaluation process, and recommendations for future evaluations are included.

\section{Questionnaire Results and Implications}

Characteristics of the study group and respondent group

Of interest as far as sex composition of the study group was that more females than males were CAPE clients. Also, females were more apt to return the questionnaire than males. It is conmon knowledge that psychiatric hospitals and mental health clinics provide treatment to more women than men. One possibility is that CAPE, like traditional mental health services, fails to reach or engage men as well as women. Two of the largest employee groups are at a school district and medical hospital, work-sites that traditionally employ a large percentage of women. This could account for more females than males seeking service from CAPE. Two. of the other companies in contract with CAPE are industrial manufacturing work-sites, where a large percentage of the employees are biue-collar males. It is possible that this group is less likely to use CAPE services. Some of the possible explanations for low utilization of mental health services by bluecollar workers were presented in chapter II. 
One of the assumptions of employee assistance programs is that traditional mental health services are not affordable by many working people. Tifty-eight percent of the study population and sixty-three percent of the respondents were in the two lower income categorles. As expected, there was a tendency for lower income respondents to report they would not have sought help elsewhere. The results of this study surgest that CAPE is accomplishinf; its goal of serving employees who otherwise would not recelve mental health services.

As can be seen from table 1 , the study group represented a range in client characteristics reparding marital status, age, and education. This clearly surrests that CAPE is serving, a variety of emlovees. Since one of the assumptions of emploiree assistance promrams is that working people tend not to utilize traditional nental health agencles, it was somewhat surprising that twenty-s.tx respondents (42 percent) had previously seen a mental health professional. However, such assumptions pertain primarily to blue-collar workers. Two of the largest employee rroups are from a hospltal and school district, worksites that are not usually associated with blue-collar work.

On rare occasions an employee is mandatorily referred to CAPE by. a supervisor. In reviewlng cllent records, over 95 percent of the clients are voluntary and CAPE does emphasize voluntarism. Fifty-four respondents ( 87 percent) soupht assistance because of psychological or emotional problems, or family or marital problems. Only one respondent indicated having alcohol as a primary problem. CAPE's emphasis on voluntartsm does seem effective for employees experiencing psychological, family, and marital problems. However, this emphasis may not be as ef- 
fective for engaging those employees who have alcohol, drug, or workrelated problems. This suggestion is made by comparing the presenting problems of the respondent group to the suggestion in the literature that 4-8 percent of any work force include employees with alcohol problems.

One of the intentions of CAPE, as with most broad-brush employee assistance proprams, is to provide assistance to employees before their job performance is impaired. Twenty-two respondents (36 percent) reported their work performance was affected by their personal problems, and twenty-two (36 percent) said it was not affected. Of interest also was that elghteen respondents (29 percent) were unsure if their work performance was affected. While lack of information precludes a definitive interpretation, it seems possible that this group of employees was unaware of on-the-job manifestations of personal problems.

That employees may not attend to how personal problems can affect work performance was further suggested by responses to question seven. The respondents who had indicated their work performance was affected by their personal problems all answered the question, "In what way was your work performance affected?" Of. the tiventy respondents who answered this question, elght (40 percent) provided replies that were considered specifically job performance impaiment. The remaining twelve (60 percent) mentioned symptoms of personal problems, but did not specify how work performance was directly affected. While the wording of the question could have contributed to a fallure to specify symptoms of work impairment, it seems possible that employees are not attuned to how personal problems affect the1r job performance. 
These results may have implications for CAPE, since one of the program objectives is to train and educate supervisors to be aware of the impatred or declining work performance of employees. These results may suggest that supervisors are not paying as much attention to job performance criteria as could be possible. If employees are unaware of job performance manifestations of personal problems, this may reflect the possibility of supervisors' also not doing so. These suggested interpretations could have implications for the CAPE staff in planning future supervisor training, or in educational efforts aimed at employees.

\section{Frocess-oriented 1tem results}

As the name implies, the Columbia Assistance Program for Employees is intended to assist troubled working people. As discussed in chapter 3, this study was intended to address the issues of physical and psychological avallabllity and accessibility. In asking clients about thelr pre-contact attitude toward CAPE, it was assumed this would provide an indication of receptivity to CAPE. Over one-half of the respondents (53 percent) Indicated a positive attitude. Since CAPE is fairly new, this does suggest that employees perceive CAPE as available to them.

Comparisons between the pre-contact attitude toward CAPE and selected questionnaire 1tems support the idea that how a client perceives a mental health agency will affect his/her experience as a cllent. As was expected, those cllents who had a positive pre-contact attitude toward CAPE tended to be the most comfortable seeking help. The importance of how an employee perceives CAPE prior to receiving 
services was evidenced by the results. Those respondents with a posit1ve attitude were inclined to report getting what they expected from CAPE. Those with a positive pre-contact attitude also tended to be the most satisfled with services, and to be the most likely to indicate they would return.

A possible implication related to these results may have to do with how CAPE introduces itself to a new company. This study did not attempt to determine why some employees have a positive attitude and others a negative attitude toward CAPE. However, it seems likely that the way in which employees inftially hear about CAPE may affect their att1tude, and more importantly, their subjective experience as a CAPE client. One further suggestion pertalns to the key company employee who is the work-site linkage person with CAPE. In some cases this is the company president, while in others it is a member of the personnel department. It seems plausible that how employees percelve this key person may color their percention of CAPE. As a consequence, CAPE staff may want to consider this possibility in choosing such a linkage person, as well as in how this person is trained and utilized.

It seems natural and predictable that people seeking help for personal problems will experience some uneasiness and anxlety. That forty-two (68 percent) of the sixty-two respondents reported feeling comfortable seeking help at CAPE strongly suggests that CAPE staff are successful in their explicit intention to provide an accepting atmosphere to troubled working people. As had been anticipated, those clients who had previous counseling experience tended to report being more comfortable seeking help than those without such experience, nine- 
teen (73 percent) versus twenty-three ( 64 percent), respectively. However, this was only a slight tendency, and the differences were not as great as expected. .

Respondents in the lower income categories did tend to report beIng more uncomfortable initially than those in the higher income categorles, nine ( 4 I percent) versus four ( 18 percent), respectively. This tendency is consistent with assertions in the literature that lower socloeconomic-level clients tend to view mental health services with more fear and suspicion than higher income clients (Stone and Crowthers 1972; Overall and Aronson 1963; Flasser, Dugran and Ioftman 1975; Free$\operatorname{man}$ and Viney 1977).

Of the sixty-two respondents 97 percent $(60)$ were seen within six days of when they called for an appointment. Jinety-seven percent also indicated satisfaction with waitine time. These results certainly indicate CAPE is successful in ensuring avallability and accessibility regarding the initial. appointment. One of the criticisms of traditional mental health arencies is that walting lists often function as an obstacle to working, people obtaintno services (Nkabas and Bellinger 1977). The above results thus demonstrate that CAPI has eliminated this obstacle for working people.

The CAPT philosophy emphasizes providing short-term or sessionIimited problem-oriented therapy. The average number of sessions for the study population was 4.6. The average nurber of sessions for the respondents was 5.5, and 3.8 for the nomrespondents. The respondents thus were seen the most number of times and the nonrespondents were seen the least number or times. While 2.3 percent (14) of the sixty- 
two respondents indicated dissatisfaction with the number of times seen, the results did not support the expectation that those seen fewer times would tend to be less satisfied. There was only a slight tendency for those respondents seen the most times to report greater overall satisfaction with services.

When clients were asked if they would have sought help elsewhere If CAPE were not avallable, elghteen (29 percent) of the sixty-two respondents said "no" and twenty-two (36 percent) were unsure. Of interest is that female respondents indicated more likelihood of seeking help elsewhere than males. This might suggest that CAPE is providing services to some males who would not otherwise consider mental health services as a source of help. As was expected, there was a strong tendency for those respondents with the least education and income to report they would not have sought help elsewhere. These results suggest that CAPE is providing services to people who would not ordinarily utilize traditional mental health services. In relation to this, there was a strong tendency for those respondents with at least a college depree and an income over $\$ 1100$ per month to indicate they would have sought services elsewhere. So while serving some employees who would not ordinarily obtain mental health servf.ces, CAPE is also serving employees who would be obtaining, services even if CAFE were not avallable.

It is often surgested in the literature that employee assistance programs provide services to employees who do not have access to traditional services. CAPE does emphasize voluntarism, and so it is expected that employees from all socioeconomic levels will utilize ser- 
vices. If the utilization rate for the blue-collar work groups was determined to be consistently lower than for other employee groups, CAPE would need to consider if this reflected problems and what could impact on this. As a fairly new program, CAPE may need to become firmly established before it is feasible to examine the composition of employees seen, and consider whether the client population reflects the type of employees that CAPE views in most need of services.

\section{Outcome-oriented item results}

The literature repeatedly suggests that most clients who respond to client satisfaction questionnaires report satisfaction with services (McPhee, Zussman and Joss 1975). This was also the case with respondents in the CAPE survey, as 86 percent of the respondents reported satisfaction with services. The results of comparisons also suggested that respondents were satisfied with services regardless of education level, income level, type of presenting problem, or involvement at survey time.

There was only a slight tendency for respondents seen more often to report satisfaction with services. Seventy-six percent (16) of the respondents seen $1-2$ times reported satisfaction, as compared to 89 percent (31) of those seen 3-10 times and 100 percent (6) of those seen over 10 times who reported satisfaction with services. These differences are not statistically significant, but could reflect possible trends. These results parallel the results of other studies, where the greater the number of sessions, the more likely a client reported satisfaction with services (Frank, Salzman and Fergus 1977).

As mentioned above, the majority of respondents reported being 
satisfled with services. Since this is a subjective measure, it can only be considered as descriptive information and is not amenable to interpretations. This measure was considered an outcome item, and as descriptive information it might be useful. The CAPE staff may want to inform the managements of the contracting companies how employees perceived their experience with CAPE.

Another item that relates to satisfaction with the outcome of services pertained to whether clients got what they expected from CAPE. Twenty-five respondents ( 40 percent) definitely got what they expected, twenty-nine ( 47 percent) indicated their expectations were somewhat met, and elght ( 13 percent) said their expectations were definitely not met. Without further information it is unknown why the responses to this item tended to be less positive than to the previous item. It was expected that those respondents whose cases were open might be more likely to Indicate their expectations were not met. This expectation was not supported, as responses were similar between those cases open and those closed.

A more indirectly phrased question pertaining: to satisfaction with the results from grolng to $\mathrm{C} \Lambda \mathrm{PE}$ was, "If you were to seek help again, would you return to CAPE?" The results to this are somewhat puzzling, as forty-four respondents (71 percent) sald they would return and eighteen (29 percent) Indicated they would not return or were unsure. If these responses are considered a report of satisfaction with outcome, they are lower than other 1tems asking about satisfaction.

Of the forty respondents whose cases were closed at the time of the survey, 35 percent (4) Indicated they were unsure if they would re- 
turn or would not return to CAPL. In comparison, of the twenty-two respondents whose cases were closed at the time of the survey, 18 percent (4) said they were unsure if they would returm to CAFE. 'The results suggest a slight tendency for those respondents whose cases were closed to more likely report reluctance to return to CAPE in the future, as compared to the group of respondents whose cases were still open.

One possibility is that the responses to this item are a more accurate reflection of client satisfaction than other items pertaining to satisfaction. This would be consistent with studies on client satisfaction that question the usefulness of varye measures of satisfaction. Such studies surrest that more specific questions regarding client satisfaction may mather more accurate assessments of client perceptions (Attkisson, Hargreaves, Horowitz and Sorensen 1978; NcPhee, Zussman and Joss 1975). Twenty-nine of the respondents either would not returm to $\mathrm{CAPE}$ or were unsure if they would. It could be inferred from these responses of how clients say they would behave, that twenty-nine percent of the respondents were not satisfied with their experience as a CAPE client.

The final item that pertained to client outcome was, "As a result of seeing, a CAPE counselor, was there a change in your work performance?" One of the major assumntions of emplovee assistance programs like CAPS is that the personal problems of employees are often brought along to the workplace and affect job performance. $\Lambda$ s a corollary to this, it is assumed that if employees obtain assistance for their problems, then job performance problems should diminish. In this study those respondents who reported job performance problems also indicated 
improved performance after recelving CAPE assistance. Fifteen of the twenty-two who reported work performance problems said their performance Improved. Of. Interest also was that of the twenty-two respondents who reported no work performance impairment, twenty (91 percent) reported no change in work performance and two ( 9 percent) sald it was improved after CAPE involvement.

Such results suggest that CAPE is accomplishing one of its major goals in providing assistance to employees whose work performance is impaired because of personal troubles. A further suggestion is that CAPE may be accomplishing its objective of being a preventive mental health service. Such a surgestion would need to assume that the group of employees not reporting job performance impairment may eventually have manifested fob performance impairment without intervention of any kind. This is a sugrestive comment, as it would seem necessary to use a control group for comparison in demonstrating such a preventive function.

Open-ended 1tem results

One of the reasons for inclusion of open-ended items in the questionnaire was to provide opportunities for clients to make comments and not be solely restricted to multiple-choice answers. Several items focused on 1ssues of avallablilty and accessibility of services. They were intended to gather information on potential obstacles to providing services to working people.

Thirty-four (56\%) of the sixty-two respondents indicated being aware of fellow employees in need of, but not recelving CAPE services. This might be a deceptive finding, since it is unknown how open em- 
ployees are among themselves regarding their utilization of CAPE services. However, some of the comments made about obstacles seem important to discuss. Subjects were asked to describe what might be making it hard for fellow employees to seek services. The stigma of mental health problems, the stigma of seeing a mental health professional, and the fallure to recognize mental health problems accounted for 92 percent of the corments made by the respondents. These comments by employees echo reports in the literature that such issues as stigma about mental 1llness and seeking help need to be addressed for mental health professionals to effectively engage troubled working people in treatment (Blanco and Akabas 1968; Stone and Crowthers 1972). The two following questions, to be discussed, were the author's attempt to obtain information from employees regarding how such obstacles might be lessened. Question number nineteen asked employees to surgest changes at the work-site that might lead to increased utilization of CAPE services. Close to one-third of the respondents suggested more publicity of CAPE services. The next most often mentioned sugrestions included more supervisor encouragemont, more information on mental health problems, and more information on the counseling process in general. Some examples of responses to this question were:

"rore clean-cut information about what is available."

"More people knowing how it works-better publicized."

"Supervisors will have to be more conscious of the interrelatedness of performance and outside problems and counsel employees to seek CAPE assistance."

"Supervisors to take more of an interest in helping, and employees not to feel threatened (job-wise) if they went." 
"Be more aware of what a psychologist is and does--
education."

"More jnservices on emotional problems."

An obvious implication is that increased or consistent publicity about available services, the various kinis of mental health problems, and the counseling process itself might lead to more utilization. The comments about suggested changes on the part of supervisors are more difficult to interpret. CAPE may want to eventually consider surveying supervisors regarding their attitudes about CAPE. Such an effort might attempt to assess what effects the supervisors' attitudes and behavior have on the utilization of CAPE services.

Question number twenty asked employees to sugrest changes at CAPE that might encourage more employees to utilize CAPE services. Again increased publicity of CAPE services was most frequently mentioned. Other suggestions included increased avallabllity and accessibility and the provision of more services. Some examples of responses to this question were:

"More people knowing how it works--better publicized."

"Would like it closer."

"More access to counselor and better follow-up."

":ore information on the types of problems helped."

"Someone on the staff to do child psycholocy work."

Question number twenty-one provided a forum for respondents to make any comments or sucgestions. Sixty-eight percent (42) of the sixty-two respondents answered this question. Of those who answered this item, 74 percent (31) made positive or complimentary comments about services or CAPF, staff, while 26 percent (11) made negative or 
clitical cormentis about services or CAPS staff. Examples of positive comments were:

"Good to know it's there and the company cares enough to provide it."

"I doubt we'd still be married if our social worker hadn't helped us to listen to each other."

"Very helpful, I will probably be back, just knowing it's there makes some experlences seem less traumatic."

"Very nice comfortable atmosphere. Zuiet and professional."

Examples of negative comments were:

"Somewhat pushy about future appointments."

"I could not see the point of all the questions. In the last evaluation I still didn't follow the ideas being said to me. Perhaps if a written evaluation were given to me would have helped so I could sit and read it."

"I expected more direct counseling."

My husband and I should have been seen separately the first time."

The responses to this item corroborate the responses to most other questions, which suggest that respondents tended to be very satisfied with most aspects of their experience with CAPE. In reviewing, the negative comments, no definite trends can be identified. The author's only sugrestion would be that it mirht be helpful for CAPS starf to be more comizant of client expectations in the inftial phase of counseling. The negative comments could imply a confusion on clients' parts regarding the purpose or process of therapy. It is also possible that the negative comnents are reflective of idiosyncratic qualities of the clients, and thus not rerlective of CAPE staff behavior. If this were the case, the author's sufgestion would be for CAPE staff to be alert to clients who may have very distorted ldeas about the purpose or pro- 


\section{Critique of the Questionnaire Response Rate}

One of the ways to assess the response rate is to compare the response rates of different studies. This is not possible with the present study, as a thorough review of the literature did not reveal any existinf cllent satisfaction studies of employee assistance programs.

The CAPE study obtained a 63 percent response rate (from ninetyelght individuals) by using one questionnatre mail-out. Also, one telephone contact was made or attempted with nonrespondents two weeks after the mail-out. In their review of client satisfaction measures; Attkisson, largreaves, Horowitz and Sorensen (1978) comment that it is often necessary to do two or three mailings alons; with telephone contact to obtaln a response rate of at least 50 percent. Taking their assessment into constderation, the 63 percent response rate with the CAPE study seems reasonably high.

It could be possible that the nonrespondents in this study were the clients least satisflod with their experience going to CAPE. A more concerted effort to convince nonrespondents to reply might have resulted in a higher response rate. IHowever, the author's concerm that multiple attempts to convince nonrespondents to reply would have had nergative consequences for how employees vlewed CAPE. For example, nonrespondents could have percelved repeated renuests for questionnaire reply as an infringement on confidentiality or as an annoyance. Such possible alienation could have been communicated to fellow ermployees, and thus reflected negatively on the CAPF program.

A nossible strategy for obtainine a hicher response rate would have been to utilize company manarement and company comunication chan- 
nels. For exarmle, encouragernent from management in a company newsletter may have increased the employee's sense of obligation to participate in the study. Also, using the company newsletter, as an altermative to a second malling to encourage questionnaire reply, may have been useful. It is possible that such strategies would introduce other biases, particularly if the authority of management was associated with this study.

The assessment of differences between respondents and nonrespondents revealed several trends. Temale subjects were more likely to reply than male subjects. The only other difference suggested pertained to involvement with $\mathrm{CAPE}$ at the time of the survey. Clients were more likely to reply to the mall-out if they were still being seen at CAPE.

\section{Critique of the Fvaluation Process, Study Group, and ouestionnaire}

Evaluation process

One of the complicating factors in planning and designing the evaluation process was incorporating both the interests of the CAPE staff and the author. Two situational factors affected the decree of involvement by CAPE staff in the planning process. At the time of evaluation planning the CAPE staff. vas quite concermed about the financial stability of the program. This necessary concem limited the time avaliable for particlpation in the evaluation process. Another factor was that the CAPT staff person most interested in program evaluation was on a leave of absence.

As much as possible the attempt was made to address the interests of the CAPE staff and the author in the evaluation planning and design. 
It is anticipated that segments of the evaluation will be of interest and use to the CAPE staff. Through the process of discussing and assessing this evaluation, it is hoped that the present study will be a springboard for future evaluation efforts.

\section{Study group}

The population chosen for this study included employees whose cases were both open and closed. As discussed previously in Chapter 4, those subjects whose cases were closed were the least likely to return the questionnaire. No differences in the kinds of responses to questionnatre 1tems were suggested between those respondents whose cases were closed versus those cases still open. If the total population of employees had been sufficiently large, the questlonnaire would have been administered to only the employees whose cases were closed. However, since it was decided to attempt to obtain a respondent group as large as possible, the questionnalre was sent to both groups.

The population chosen for this study included employees of contracted comoanies, employees and family member(s), and family member(s) without the employee. No attempt was made to alfferentlate these groups In the analyses of responses. It is conceivable that this characteristic could have Influenced the response rate and the content of the responses. When couples or familles were the clients, the employee of the CAPE-contracted company was sent the questionnaire. The spouses or family members could have influenced whether the employee completed the questionnaire as well as the content of responses. In retrospect an alternative strategy would have been to send a questionnaire to each Individual who participated in counseling at CAPE. 
Questionnaire

An analysis of the questionnaire used in this study reveals several possible problems. Since the questionnaire was constructed specifically for this study, a comparison with other studies to assess questionnaire reliablilty and validity was not an option. Furthermore, the use of client satisfaction measures with employee assistance programs is nonexistent as far as the author was able to determine. A search of the literature as well as a survey of employee assistance programs around the country did not reveal any programs utilizing client satisfaction measures.

The questionnaire was desimed to gather information on process and outcome issues as well as on characteristics or the respondents. The breadth of the study time precluded the elicitation of detalled information. Several examples of this fallure to obtain in-depth information can be identified. While question number one did result in a. global assessment of employees' attitudes about CAPE prior to contact, it is unknown what contributed to a positive or negative attitude. Consequently, this descriptive data does not provide useful information for planning an attempt to impact the pre-contact attitudes of employees toward CAPS:

Ouestion number three asks subjects whether they had previously seen a mental health professional. Agrain it is not known what kind of experience this was. It is uncertain whether their previous experience or non-experience had implications for what the employee thought about CAPE or expected from the CAPE staff.

Question number seven was open-ended and allowed the respondents 
to describe how their work performance was affected by personal problemis. A content analysis of the responses was done to categorlze this information. A review of the responses suggested some confusion on the part of respondents. Respondents seerned to have trouble distinguishing symptoms of personal problems from evidence of job performance difficulties. A checklist of common job performance problems may have reduced the confusion regarding this issue and provided more useful information.

The questions pertaining to client satisfaction were similar to those used in various other client satisfaction studies (Attkisson, Hargreaves, Horowitz and Sorensen 1978). It does seem important for CAPE to know the degree to which clients are satisfled with services and the results of getting assistance. Ilowever, the global nature of such questions fails to ascertain which aspects of services, staff. behavior, or outcome are satisfying or dissatisfyine to clients.

Question number sixteen allowed the employee to Indicate if their work performance had 1mproved or not, as a result of CAPE services. A checklist of job performance levels could have been used here, rather than the "yes" or "no". answers. The speclfic examples of how job performance had improved would have been identified.

The open-ended questions resulted in a variety of responses. Some were expected by the author while others were not. One concerm with the open-ended items is that roughly one-third of the respondents failed to answer these questions. It is possible that having four openended 1tems at the end of the questionnaire were too many. Elther havIng fewer open-ended 1tems or spreading them throughout the question- 
naire may have increased the response rate. It also seems possible that the wording of these items may not have been satisfactory. The administration or a pre-test on a sample of employees may have been useful In constructing the questionnaire.

Future Evaluations: Discussion and Recommendations

The study described in this report was a one-time client satisfaction survey. The questionnaire was multi-dimensional in focus. It assessed client satisfaction with process and outcome issues as well as gathered information on characteristics of CAPE clients. Many trends were suggested from the results, but more questions were raised than answered. It is anticipated that some informational trends will assist the CAPE staff in formulating objectives for future evaluation studies.

One possiblitty for future evaluations is the establishment of an ongolng evaluation system. One advantage to an ongoing client satisfaction system would include the opportunity for employees to continuously provide feedback to CAPE. Another would be that CAPE could have current information on clients that might be useful in decision-making. One obvious disadvantage to an ongoing system would be the need for continuous commitment of staff time to such efforts. Another would be the possibllity of producing more data than CAPE could utilize on an ongoing basis. CAPE is a falrly new program that is working toward firm establishment in the community. The advantages and disadvantages of an ongoing system would need to be considered as well as the priorities of the CAPE program.

This study was solely concerned with employees and their family members who recelved CAPE services. Several other potential target 
populations for evaluation studies can also be identified. One possibility would be surveying supervisors as to thelr acceptance, understanding, and utilization of CAPE services. The present study did indicate that some emplovees thought supervisors needed to be more involved in advocating utilization of available services. Another possibllity would be a survey of those employees who have not utilized CAPE services. Such an investigation might provide information regardIng why some employees do not use CAPE services. The objectives of surveying non-users might be to increase or alter utilization patterms with a particular company or problem type. Such a survey might also have as its goal to understand causes of low utilization and to develop strategies for change.

Cost-benefit analysis is one kind of evaluation that is of interest to the CAPE staff. This type of evaluation stratery was briefly discussed in chapter 2, but is not addressed in this study.

There are many possible strategies to choose from in looking at cost-benefit. A stratepy that is frequently mentioned in the literature is the comparison between employees who have received assistance and a control group of employees who have not recelved assistance. The study would then look at selected job performance variables such as absen-. teeism and on-the-job accidents. These kinds of studies typically compare the groups over a one to three year period. This may also be a premature strategy for CAPE. Large study populations are usually used In cost-beneflt analyses and are most likely to reveal meaningful differences. Since the CAPE staff as well as potential contracting companies are interested in cost-benefit studies, the exploration of 
strategies for implementing such studies is recommended.

The intention and emphasis of an evaluation reflect the values and interests of a program. The process of doing cost-benefit studies may provide useful information as well as have unanticlpated consequences. Cost-benefit studies might serve the interests of CAPE, since results might indicate CAPE is saving money for a business or industry. This data could then be of use in marketing CAPE services. Cost-benefit studies would also serve the interests of business and industry, since they would find out if their financlal investment in CAPE was paying off.

While cost-benefit studies can provide useful information, non emphasis on cost-beneflt could overlook the interests of the employee. It would seem important to be compizant of the possibility of alienatIng employees, and CAPE being seen as only an arm of management. Such possible negative consequences to cost-benefit studies could be minimized by careful attention to the processes involved in cost-benefit evaluations. For example, the issue of confidentiality would need to be addressed, since employees might consider data or absenteelsm and medical utilization as private information. Another important issue would be managements' attitudes regarding the results of cost-benefit studies. It would be important that employees not perceive their job security as endangered by such research. Another possible issue would be the attitude of the employees' union regarding such research. Costbenefit studies seem very promising, especially if mental health professionals are to pursue the world of work as a place for mental health programing. Finally, it would seem wise to consider the foregoing 
Issues surrounding cost-benefit studies, if and when CAPE plans and designs such evaluation efforts.

\section{Conclusion}

The results of this study have been discussed in chapter 4 and the preceding sections of chapter 5. A discussion of the questionnaire results and the implications of the study have been presented. A critique of the questionnaire response rate, the evaluation process, the study group, and the questionnaire were presented. Finally, recommendations for future evaluation efforts at CAPE were proffered.

The CAPE staff were not involved in the analysis of data, and while data from this study were not presented to the CAPE staff on a continuous basis, an occasional effort was made to inform CAPE staff of the evaluation process. Consequently, the final step in the evaluation process will be the presentation of study results to the CAPE staff. This study did generate information that was not utilized in this report, but that may be useful to the CAPE starf or the contracted companies. For example, cross-tabulations were done between individual CAPE staff and a ranpe of questionnaire 1tems. These analyses were generated solely for the staff's benefit, at the request of the CAPE training director. Cross-tabulations were also done between the company employee-groups and a variety of questionnalre items. In examining these results with $C \Lambda P E$ staff, a decision will be made as to possible utilization of such data.

The evaluation study at CAPT was the research component to this report on industrial social work. The literature review in chapter 2 covered a broad range of issues, some addressed in more detail than 
others. This comprehensiveness in focus was consistent with the author's initial intention of providing a review of many of the issues relevant to mental health programing in the world of work. The evaluation study at CAPE was the attempt to both describe and assess an employee assistance program. It is hoped that this report as a whole provides a perspective for understanding some of the complex Issues that are involved in the efforts of mental health professionals to interface with the world of work. 
APPENDIX A

COPY OF QUESTIONNAIRE AND COVER IEITTER 


\section{SURVEY OF CAPE CLIENTS}

We are interested in your honest opinions, whether they are positive or negative. Please answer all of the questions.

1. Before your contact with CAPE, what was your personal attitude toward CAPE? (check answer that best $f$ its you)

(01) Definitely positive

(04) Somewhat negative

(02) Somewhat positive

(05) Definitely negative

(03) No opinion

2. From what source did you hear about the CAPE program?

(01) Publicity (brochures, articles in newsletters)

(02) CAPE staff (05) Supervisor

(03) Fellow employees___ (06) Family member

(04) Personnel Dept.

(07) Other

3. Before your contact with CAPE, had you ever seen a mental health professional(counselor, psychiatrist, psychologist, social worker) for personal reasons? (01) Yes

(02) No

4. How comfortable were you seeking help for personal problems? (01) Very comfortable (04) Somewhat uncomfortable

(02) Somewhat comfor table

(05) Very uncomfortable

(03) No opinion

5. What was the primary difficulty you were having that led to going to CAPE? (check one)

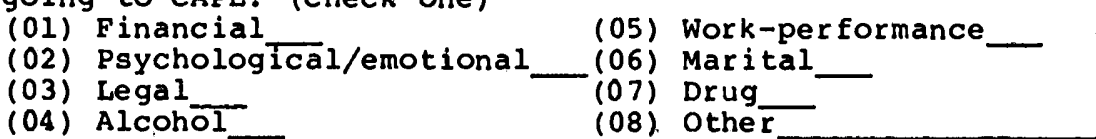

6. Did the difficulty you were having influence your work performance? (check one)
(01) Yes
(02) Not sure
(03) No

7. If Yes to the above, in what way was your work performance affected?

8. Once you called CAPE for an appointment, how long was it before you were seen? (check one)

(01) seen the same day

(02) 1-2 days

(04) 4-6 days

(03) 3-4 days

(05) over 6 days

9. Was this soon enough for you? (check one)
(01) Yes (soon enough)
(02) No(not soon enough)

10. What was the total number of times you were seen by a CAPE staff? (write the number)

11. Was this enough for you? (check one)
(01) Yes, more than enough
(03) No, not nearly enough

(02) Just right

(Continue on other side) 
12. Did you get what you expected from going to CAPE? (check one)
(01) Yes, definitely
(02) Somewhat
(03) No, definitely not

13. If CAPE had not been available, would you have sought help elsewhere from a mental health professional? (check one)
(01) Yes
(02) Don't know
(03) No

14. In an overall sense, how satisfied are you with the services you received from CAPE? (check one)

$\begin{array}{ll}\text { (01) Very satisfied } & (04) \text { Mildly dissatisfied } \\ \text { (02) Mildy satisfied } & (05) \text { Very dissatisfied }\end{array}$

(02.) Mildiy satisfied

(03) No opinion

15. If you were to seek help again, would you come back tocAPE?

(01) Yes, definitely

(02) Not sure

(03) No, definitely not

16. As a result of seeing a CAPE counselor, was there a change in your work performance?

(01) Improvement_ (02) No change___ (03) Got worse

17. Do you know fellow employees who might benefit from the services at CAPE, but don't go? (check one)
(01) Yes
(02) No

18. If Yes to \#17, what do you think might be making it hard for them to go?

19. What do you think would need to change at your place of employment for more people to use CAPE services?

20. What do you think would need to change about CAPE for more people to use CAPE services?

21. Any comments or suggestions about your experiences with CAPE?

Thank you for your help: 
P.O. Box 214

Marylhurst, OR. 97036

January 11, 1979

Dear CAPE client,

W111 you do us a favor?

We are conducting a survey among all employees who have had contact with the CAPE program. The purpose of this survey is to find out your opinions of CAPE services. Your answers will help the CAPE program know if it is providing the services you need, and will assist us in improving how we provide services to future clients. By knowing your opinions we also hope to be able to improve the employee assistance program offered through your company.

Of course all answers are strictly confidential. The names of Individual clients won't be known to anyone outside of our research team. Please feel free to call me at 635-4339 if you have any questions.

It will take only a short time to answer the questions on the enclosed questionaire. We enclose a stamped reply envelope for your convenience, and ask that you return the questionaire by January 22 .

Thank you for your help.

\author{
Sincerely yours, \\ Gregory Lee \\ Research Coordinator
}


APPENDIX B

TABLES OF COMPARISONS BETWEEN

SEX AND QUESTIONNAIRE ITEMVIS

TABLE 33

Sex by Pre-contact Attitude Toward CAPE

Positive No Opinion Negative Row Total

Sex:

$\begin{array}{ccccc}\text { Male } & 9 & 5 & 1 & 15(24 \%) \\ \text { Female } & 24 & 21 & 2 & 47(76 \%) \\ \text { Colum Total: } & \frac{24}{33}(53 \%) & \frac{21}{26}(42 \%) & \frac{2}{3}(5 \%) & \frac{47}{62}\end{array}$

TABIE 34

Sex by Previous Counseling Experience

Yes No Row Total

Sex:

$\begin{array}{cccc}\text { Male } & 6 & 9 & 15(24 \%) \\ \text { Female } & 20 & 27 & \frac{27}{36}(76 \%) \\ \text { Colum Total: } & \frac{20}{26}(42 \%) & \frac{47}{62}\end{array}$


APPENDIX B-Continued

TABLE 35

Sex by Comfort Seeking Help

Comfortable

Uncomfortable

Row Total

\begin{tabular}{llll}
\hline Sex: & & & \\
Male & 11 & 4 & $15(24 \%)$ \\
Female & $\frac{31}{42}(68 \%)$ & $\frac{16}{20}(32 \%)$ & $\frac{47(76 \%)}{62}$ \\
Colum Total: & & \\
\hline
\end{tabular}

TABLE 36

Sex by Would Return to CAPE

Yes

No

Row Total

Sex:

Male

Female

Column Total:

10

$\frac{33}{43}(69 \%)$

$\frac{5}{14}$

15. $(24 \%)$

$47(76 \%)$

62 


\section{APPENDIX C}

TABLES OT COIPARISOISS BETTEEN

EDUCATION AND QUESTIONNAIRE IIENIS

\section{TABLE 37}

Education by Pre-contact Att1tude

\begin{tabular}{ccccc}
\hline & Positive & No Opinion & Negative & Row Total \\
\hline $\begin{array}{c}\text { Education: } \\
\text { HS or Less } \\
\text { Technical Train- } \\
\quad \text { Ing or Some }\end{array}$ & 9 & 9 & 1 & $19(32 \%)$ \\
College & 11 & 9 & 1 & $21(35 \%)$ \\
BA, Mn, Ph.D. & $\frac{13}{33}(55 \%)$ & $\frac{7}{25}(42 \%)$ & $\frac{0}{2}(3 \%)$ & $\frac{20(33 \%)}{60}$ \\
Colum Total: & & & & \\
\hline
\end{tabular}

\section{TABLE 38}

Education by Comfort Seeking Help

Comfortable Uncomfortable Row Total

Education:

HS or Less

Technical Training or Some College

$B A$, I:A, Ph.D.

Colum Total:
12

7

$19(32 \%)$

14

$\frac{15}{4 I}(68 \%)$ $\frac{7}{5}$
$\frac{5}{19}(32 \%)$
$21(35 \%)$

$20(33 \%)$ 
APPENDIX C--Continued

\section{TABLE 39}

Education by Number of Times Seen

\begin{tabular}{lllll}
\hline \hline & $1-2$ & $3-10$ & Over 10 & Row Total \\
\hline $\begin{array}{l}\text { Education: } \\
\text { HS or Less }\end{array}$ & 9 & 10 & 0 & $19(32 \%)$ \\
$\begin{array}{l}\text { Technical Training } \\
\text { or Some College }\end{array}$ & 7 & 10 & 4 & $21(35 \%)$ \\
BA, MA, Ph.D. & $\frac{5}{21}(35 \%)$ & $\frac{14}{34}(57 \%)$ & $\frac{1}{5}(8 \%)$ & $\frac{20(33 \%)}{60}$ \\
Column Total: & &
\end{tabular}

TABLE 40

Education by Satisfaction with Number of Sessions

Yes :To Row Total

Education:

HS or Less

Technical Training or some Collepe

BA, MA, Ph.D.

Column Total:
15

4

$19(32 \%)$

15

$\frac{17}{47}(78 \%)$
6

$21(35 \%)$

$\frac{3}{13}(22 \%)$

$20(33 \%)$

TABLE 41

Education by Whether Expectations Were Met

Yes

Somewhat No

Row Total

Education:

HS or I.ess

Technical Training or Some College BA, MA, Ph.D. Column Total:
10

6

3

$19(32 \%)$

\begin{tabular}{rr}
7 & 12 \\
8 & 9 \\
\hline
\end{tabular}

$25(42 \%)$ 
APPENDIX C--Continued

TIABLE 42

Education by Overall Satisfaction with Services

Satisfied

Dissatisfied

Row Total

Education:

HS or Less

Technical Tratning or Some College

BA, MA, Ph.D.

Column Total:
15

18

18

$51(35 \%)$
4

19. $(32 \%)$

$21(35 \%)$

$20(33 \%)$

TABLE 43

Education by Would Return to CAPE

Yes

No

Row Total

Education:

HS or Less

Technical Training or Some Collere

$B A, M M, P 3 . D$.

Colum Total:
12

15

14

पI $(63 \%)$
3
$\frac{2}{9}(15 \%)$ 


\section{APPESIDIX D}

TABIES OF CORTARISONS BETWEEN

IICOIE AND QUESTIONNAIRE IIE'SS

TABIE 44

Income by Pre-contact Attitude Toward CAPE

Positive

No Opinion

Negative

Row Total

Income:

\begin{tabular}{ccccc}
$500-799$ & 10 & 10 & 2 & $22(39 \%)$ \\
$800-1099$ & 11 & 6 & 0 & $17(30 \%)$ \\
$1100-1399$ & 6 & 4 & 1 & $11(20 \%)$ \\
$1400-1999$ & 4 & $\frac{2}{22}(39 \%)$ & $\frac{0}{3}(5 \%)$ & $\frac{6(11 \%)}{56}$ \\
\hline
\end{tabular}

TABZIF 45

Income by Previous Counseling Experience

Yes

NTO

Row Total

Income:

500-799

800-1099

1100-1399

1400-1999

Colurm Total:

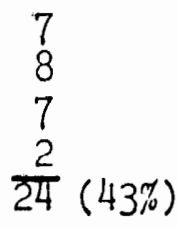

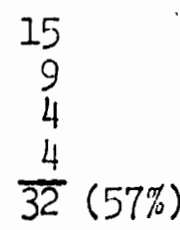

$22(39 \%)$

17 (30\%)

$11(20 \%)$

$6(11 \%)$ 
APPENDIX D-Continued

\section{TABLE 46}

Income by Number of Times Seen

1-2 3-10 Over 10 Row Total.

Income :

\begin{tabular}{|c|c|c|c|c|}
\hline $\begin{array}{c}500-799 \\
800-1099 \\
1100-1399 \\
1400-1999 \\
\text { olumn Total: }\end{array}$ & $\begin{array}{l}6 \\
8 \\
3 \\
2 \\
\frac{2}{19}(34 \%)\end{array}$ & $\begin{array}{r}14 \\
7 \\
7 \\
4 \\
\frac{4}{32}(57 \%)\end{array}$ & $\begin{array}{l}2 \\
2 \\
1 \\
0 \\
\frac{1}{5}(9 \%)\end{array}$ & $\begin{aligned} 22 & (39 \%) \\
17 & (30 \%) \\
11 & (20 \%) \\
6 & (11 \%) \\
56 & \end{aligned}$ \\
\hline
\end{tabular}

TINELE 47

Income by Sat1sfaction with Number of Sessions

Yes

No

Row Total

Income:

$\begin{array}{lrll}500-799 & 16 & 6 & 22(39 \%) \\ 800-1099 & 14 & 3 & 17(30 \%) \\ 1100-1399 & 8 & 3 & 11(20 \%) \\ 1400-1999 & 6 & 0 & 6(11 \%) \\ \text { Total: } & \frac{6}{44} \cdot(79 \%) & \frac{1}{12}(21 \%) & 56\end{array}$

Column Total:

TABLE 48

Income by Whether Expectations Were l.et

Yes Somewhat No Row Total

Income:

$\begin{array}{llrll}500-799 & 11 & 8 & 3 & 22(39 \%) \\ 800-1099 & 6 & 10 & 1 & 17(30 \%) \\ 1100-1399 & 3 & 5 & 3 & 11(20 \%) \\ 1400-1999 & \frac{2}{22}(39 \%) & \frac{4}{27}(48 \%) & \frac{1}{7}(13 \%) & \frac{6}{56}(11 \%) \\ \text { Total: } & \frac{11}{21}\end{array}$




\section{APPENDIX D-Continued}

TIABLE 49

Income by Overall Satisfaction with Services

Satisfled

Dissatisfied

Row Totạl

Income:

$500-799$

800-1099

$1100-1399$

1400-1999

Column Total:

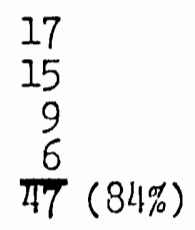

TABLE 50

Income by Would Return to CAPE

Yes

No

Row Total

Income: 500-799

800-1099

1100-1399

1400-1999

Column Total:
16

14

\begin{tabular}{l}
5 \\
5 \\
\hline
\end{tabular}

$\frac{5}{40}(71 \%)$

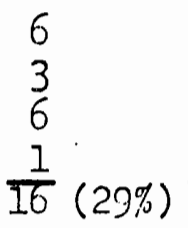

$22(39 \%)$

$17(30 \%)$

$11(20 \%)$

$6(11 \%)$
$22(39 \%)$

$17(30 \%)$

$11(20 \%)$

$6(11 \%)$ 


\section{APPEINDIX E}

TAABLISS OF COMPARISOIJS - BETWEEN

PRESENTING PROBLENS AND QUESTIONIAIRE ITEN'L

\section{TABLE 51}

Presenting Problems by Whether Expectations Were Met

\begin{tabular}{lrrrr}
\hline \hline & Yes & Somewhat & No & Row Total \\
\hline Presenting Problems: & & & & \\
Psychologlcal & 12 & 13 & 4 & $29(47 \%)$ \\
Alcohol & 0 & 1 & 0 & $1(2 \%)$ \\
Work-related & 2 & 3 & 2 & $7(11 \%)$ \\
Marltal or Family & $\frac{11}{25}(40 \%)$ & $\frac{12}{29}(47 \%)$ & $\frac{2}{8}(13 \%)$ & $\frac{25(40 \%)}{62}$ \\
Colum Total: & & & \\
\hline
\end{tabular}

TABLE 52

Presenting Problems by Would Seek Help Elsewhere.

Yes Don't ínow No . Row Total

Presenting Problems:

Psychological

Alcohol

Work-related

Marital or Family II

Colum Total:
10

0

1

$\frac{11}{22}(36 \%)$
13

0

$\frac{1}{8}$

$\begin{array}{crr}6 & 29 & (47 \%) \\ 1 & 1 & (2 \%) \\ 5 & 7 & (11 \%) \\ 6 & 25 & (40 \%) \\ \frac{18}{18}(29 \%) & \frac{6}{62}\end{array}$


APPENDIX E-ContInued

TABLI 53

Presenting Problems by Overall Satisfaction with Services

Satisfied

Dissatisfied

Row Total

Presentine Problems:

Psychological

Alcohol

Work-related

24

Marital or Family

Column Total

$\frac{1}{4}$

5

0

3

24

$53(86 \%)$

$\frac{1}{9}(15 \%)$

$29(47 \%)$

$1 \quad(2 \%)$

7 (11\%)

$25(40 \%)$

62 


\section{APPENDIX F}

TABLES OF CONDARISONS BETWEEN PIE-CONMACT

ATTITUDE AND NUESTIONNAIRE TTTMS

\section{TABLE 54}

Pre-contact Attitude by Previous Counseling Experience

$\begin{array}{lll}\text { Yes No Now Total } & \text { No }\end{array}$

Pre-contact Atti.tude:

Positive

No Opinton

Negative

Colum Total:
13

12

$\frac{1}{26}(42 \%)$
20

14

$\frac{2}{36}(58 \%)$
$33(53 \%)$

$26(42 \%)$

$3(5 \%)$

TABLE 55

Pre-contact Attitude by Overall Satisfaction with Services

Pre-contact; Attitude:

Positive

No Opinion

Negative

Column Total:
31

20

$\frac{2}{53}(86 \%)$

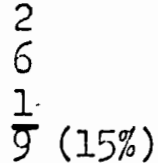

$33(53 \%)$

$26(42 \%)$

$\frac{3 \quad(5 \%)}{52}$ 


\section{AFPENDIX G}

TABLES OF COMPARISONS BETWEEN COMFORT

SEEKING HELP AID NUESTIONNAIRE ITEISS

\section{TABLE 56}

Comfort Seeking Help by Whether Expectations Were ilet

Yes Somewhat No Row Total

\section{Comfort Level:}

Comfortable

Uncomfortable

Colum Total:

$\begin{array}{llll}20 & 16 & 6 & 42(68 \%) \\ \frac{5}{25}(40 \%) & \frac{13}{29}(47 \%) & \frac{2}{8}(13 \%) & \frac{20(32 \%)}{62}\end{array}$

TABLE 57

Comfort SeekIn HeIp by Would Seek Help Elsewhere

Comfort Level:

Comfortable

Uncomfortable

Column Total:
37

16

$53(86 \%)$

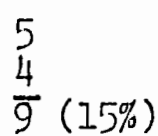

$42(68 \%)$

$20(32 \%)$ 


\section{APPENDIX G-Continued}

\section{TABLE 58}

Comfort Seeking Help by Overall Satisfaction with Services

Comfort Level:

Comfortable

Uncomfortable

Column Total:

37
16

$53(86 \%)$ $\frac{5}{4}$

$\overline{9}(15 \%)$
$42(68 \%)$

$20(32 \%)$ 


\section{LIST OF REIERENCES}

Akabas, Sheila H. "Mental Health Program Models: Their Role in Reducing Occupational Stress," Paper presented at a Conference on Reducing Occupational Stress, White Plains, N. Y., May 1977.

Akabas, She1la H. and Seth A. Akabas. "Mentally Restored Persons Can Work: Strategles for Improving Job Opportunlties and Placements," Report delivered at a National Conference on the Community Imperative, Washington, D. C., June 1, 1978.

Akabas, She1la H. and Susan Bellinger. "Programmine Mental Health Care for the World of Work," Mental Health, 61 (Soring 1977): 4-8.

Akabas, Sheila H. and Susan Bellinger. "Employee Counseling Programs: A Sample," Unpublished paper, Industrial Social Welfare Center, Columbia University School of Social Work, N. Y., July 1977.

Alrabas, She1la H., Paul A. Kurzman and Nancy S. Kolben. Labor and Industrial Settincs: Sites for Social Work Practice. New York: Council on Social Work Education, 1979.

Attkisson, C. Clifford, W. A. Harpreaves, M. J. Horowitz and J. E. Sorenson. Evaluation of Ilurian Service Programs. New York: Academic Press, 1978.

Austin, Michael J. and Erwin Jackson. "Occupational Mental Health and the Human Services: A Review," Health and Social Work, 2 (February 1977): 93-118.

Benedict, David Speare. "A Generalist Counselor in Industry," Personnel and Guidance Journal, 51 (June 1973): 717-722.

Blarico, Antonio and Sheila II. Akabas. "The Factory: Site for Community Mental Ilealth Practice," American Joumal of Orthopsychiatry, 38 (April 1968): 543-553.

Bloom, Bernard I. Comminity Mental Health: A Historical and Critical Analysis. Mormlstown, N. J.: General Learning Press, 1973.

Brooks, Michael P. "The Community Action Promram As a Setting for Applied Research," in Francls $G_{0}$. Caro, ed., Readines in Evaluative Research. New York: Russell Sage Foundation, 1971, pp. 53-62.

Brooks, Paul R. "Industry-agency Program For Employee Counseling;" Soc1al Casework, 56 (JuIy 1975): 404-410. 
Brown, Bertram S. Obstacles to Treatment For Blue-Collar Workers. Report from the Director, National Institute of Mental Health, U. S. Department of Health, Education, and Welfare, June 1976.

Bureau of National Affairs. Counseling Policies and Programs for Employees with Problems. ASPA-BNA Survey No. 34. Washington, D. C.: Bureau of National Affairs, March 1973.

Chommle, Peter W. and Joe Hudson. "Evaluation of Outcome and Process," Social Work, 19 (November 1974): 682-687.

Collier, Bermard L. "Industrial Psychology on the Line," Psychology Today, 12. (July 1978): 66-76.

Dahl, Carl W. et al. Solving Job Performance Problems. State of Florida: Department of Health and Rehabilitative Services, 1978.

EfthIm, Alex. "Serving the U. S. Work Force: A New Constituency For Schools of Soclal Work," Journal of Education for Soclal Work, 12 (Fall 1976): 29-36.

Frank, Rafael, Ken Salzman and Esther Fergus. "Correlates of Consumer Satisfaction with Outpatient Therapy Assessed By Postcards," Community Mental Health. Joumal, 13 (Spring 1977): 37-45.

Freeman, R. Beth and Iinda L. Viney. "Patient's Expectations of the Therapist Role," Journal of Cormunity Psychiatry, 5 (1977): 372-379.

Freud, Slgmund. Civilization and Its Discontents. Translated and edited by James Strachey. New York: W. W. Norton, 1961.

Ginzberg, El1. "Technological Change and Adjustment to Work," Jourmal of Occupational ledicine, 9 (May 1967): 232-238.

Glasser, M. A., T. J. Dugran and W. S. Iloffman. "Obstacles to Utilization of Prepald Mental Health Care," American Joumal of Psychiatry, 132 (July 1975): 710-715.

Googins, Bradley. "Employee Assistance Programs," Soclal Work, 20 (November 1977): $464-467$.

Gould, Robert E. "Dr. Strangeclass: Or How I Stopped Worrylng about the Theory and Began Treating the Blue-collar Worker, "American Journal of Orthopsychiatry, 37 (January 1967): 78-86.

Gyllenhammer, Pehr. People At Work. Reading, Mass.: Addison-Wesley, 1978.

Hellan, Richard T. and Carl R. Stone. "Employee Assistance Programing: Personnel's Sobering Influence on the Bottom Line," Report from 
The American Society For Personnel. Administration, Berea, Ohio, n.d.

Helma, Thomas. "The Missing Link: A Proposal on How to Get People to Mental Health Services Before They Lose Their Jobs," Unpublished paper, Ingham Community Mental Health Center, Ingham, Michigan, 1978.

Joerger, James H. "Epidemiolory, Costs, and Cost Effectiveness of Industrial Alcoholism and the Employee Assistance Programs," Unpublished paper, Columbja Assistance Program for Employees, Marylhurst, OR., 1978.

Knight, Paul. "Public Welfare and Work: A Study of Transition," Unpublished paper, Portland State University, School of Social Work, 1977.

Levenson, Alan I. "Implications of Community Mental Health Programs For Industry," American Joumal of Public Health, 60 (October 1970): 1931-1935.

McIean, Alan A. "Occupational Mental Health: Review of an Emerging Art," American Jourmal of Psych1atry, 122 (March 1966): 961-975.

McPhee, Carol B., Jack Zussman and llobert H. Joss. "Measurement of Patient Satisfaction: A Survey of Practices in Community iental Ilealth Centers," Comprchensive Psychiatry, 16 (Julv-August 1975): $399-404$.

New York Times. "Pore Care Given Firmloyees' Psyches," I April 1979, sec. 3, pp. $13,4$.

o'Toole James. Work, Leaminr, and the American Future. San Franc1sco: Jossey-Rass, 1977.

Overall, Betty and H. Aronson. "Expectations of Psychotherapy in Patients of. Lower Socloeconomic Class," American Journal of Orthopsychiatry, 33 (Apri1 1963): 421-430.

Powell, Barbara J., David Shaw and Carole ONeal. "Client Evaluation of a Clinic's Services," Hospital and Communjty Psychiatry, 22 (June 1971): 189-190.

Rappaport, Maurlce, Michael P. Dolan and Toni Clementi. "Psychological Problems in an Industrial Setting," Joumal of Occupational Medicine, 19 (October 1977): 659-663.

Riessman, Jrank and Sylvia Scribner. "The Underutilization of Mental Health Services by Workers and Low Income Groups: Causes and Cures," American Journal of Psychiatry, 121 (February 1965): 798-801. 
Roman, Paul. "Secondary Prevention of Alcoholism: Problems and Prospects in Occupational Programning," Jourmal of Drug Issues (Fall 1975): $327-343$.

Smart, Reginald $x_{\text {. }}$ "Employed Alcoholics Treated Voluntarily and Under Constmuctive Coercion," Muarterly Journal of Studies on Alcohol, 35 (1974): 196-209.

Sommer, John J. "Work as a Theraneutic goal: Union-Management Clinical Contributions to a "Iental Healt' Program," Mental Hygiene, 53 (April 1969): 263-268.

Stone, Judson I. and Virginia Crowthers. "Innovations in Program and Funding of "Tental Health Services for Blue-collar Families," American Joumal of Psychlatry, "28 (May 1972): 1375-1380.

Talkington, Joe. Innublished program description, Columbia Assistance Program for Imployees, Marylhurst, OR., 1978.

Tapscott, John. "The Des MoInes Success Story," Labor-Management Alcoholism Journal (July-August 1978): 25-30.

Tilgher, Adriano. "tork Through the Ages," in Sigmund Nosow and William H. Form, eds., Man, Work and Soclety. New York: Basic Books, 1962 .

Trice, Harrison. "Alcoholism and the Nork World," Sloan Management Review, 12 (Fall 1970): 67-75.

Trice, Harrison, Janice M. Beyer and Richard E. Hunt. "Evaluating Implementation of a Job-Based Alcoholism Policy," Journal of. Studies on Alcohol, 19 (1978): 448-465.

Weiner, Hrman J. and Sheila H. Alkabas. "Work in America: The View from Industrial social Welfare," Inpublished naper, Inlustrial social Welfare Center, Columbia University School of 'Social Work, June 1974 .

Weiner, Hyman J., She1la H. Nkabas and John J. Sommer. Nental Health Care in the World of Work. New York: Association Press, 1973.

Weiss, Robert S. and Martin Rein. "The Evaluation of Broad-Aim Programs: A Cautionary Case and a loral," Administrative Science Quarterly, 15 (1970): 97-109.

Welssman, Andrew. "Industrial Social Services: Linkage Technology," Social Casework, 57 (January 1976): 50-54.

Wiegand, Ross A. "An Effective Approach to Fmployee Alcoholism," The Personnel Administrator (July-August 1972). 
Yankelovich, Daniel. "Ihe Meanins of Nork," in Jerone M. Rosow, ed., The Worker and the Job. Englewood Cliffs, N. J.: Prentice-Hail, 1974. 